\title{
Radiative Fluxes in the ECHAM5 General Circulation Model
}

\author{
MARTIN WILD \\ Institute of Atmospheric and Climate Science, ETH, Zurich, Switzerland \\ ERICH ROECKNER \\ Max Planck Institute for Meteorology, Hamburg, Germany \\ (Manuscript received 30 November 2004, in final form 8 August 2005)
}

\begin{abstract}
Radiative fluxes in the ECHAM5 general circulation model (GCM) are evaluated using both surface and satellite-based observations. The fluxes at the top of the atmosphere (TOA) are generally in good agreement with the satellite data. Larger deviations in simulated cloud forcing are found especially at lower latitudes where the shortwave component within the intertropical convergence zone is overestimated during boreal summer and underestimated in the marine stratocumulus regimes, especially during boreal winter. At the surface the biases in the radiative fluxes are significantly smaller than in earlier versions of the same model and in other GCMs. The shortwave clear-sky fluxes are shown to be in good agreement with newly derived observational estimates. Compared to the preceding model version, ECHAM4, the spurious absorption of solar radiation in the cloudy atmosphere disappears due to the higher resolution in the nearinfrared bands of the shortwave radiation code. This reduces the biases with respect to collocated surface and TOA observations. It is illustrated that remaining biases in atmospheric absorption may be related to the crude aerosol climatology, which does not account for high loadings of absorbing aerosol such as from biomass burning, whereas the biases disappear in areas and seasons where aerosol effects are less important. In the longwave, the introduction of the Rapid Radiative Transfer Model (RRTM) radiation code leads to an increase in the longwave downward flux at the surface at high latitudes, thereby reducing biases typically found in GCMs. The considerable skill in the simulation of the fluxes at the earth's surface underlines the suitability of ECHAM5 as an atmospheric component of an integrated earth system model.
\end{abstract}

\section{Introduction}

The sun is the only significant source of energy for planet Earth. Extensive satellite programs such as the Earth Radiation Budget Experiment (ERBE) and the Clouds and the Earth's Radiant Energy System (CERES) experiment have been established to determine the amount of solar energy absorbed by the globe and radiated back to space in the form of thermal radiation (Barkstrom et al. 1990; Wielicki et al. 1996). The accurate representation of this energy balance in GCMs is a basic prerequisite for an adequate simulation of the energy content of the planet. In addition, it is of key importance how this energy is further distributed within the climate system, particularly at the sur-

Corresponding author address: Martin Wild, Institute for Atmospheric and Climate Science, ETH, Swiss Federal Institute of Technology, Universitaetsstr. 16, CH-8092, Zurich, Switzerland. E-mail: martin.wild@env.ethz.ch face. The net radiation at the surface is the principal driver of the global hydrological cycle. The earth's surface also forms the interface between different components of the climate system, that is, the atmosphere, on the one hand, and the ocean, land surfaces, biosphere, and cryosphere (glaciers, sea ice), on the other hand. It is essential that the energy fluxes at these interfaces are well determined when attempting to couple models of these components into comprehensive climate system models. Ma et al. (1994), for example, showed that the coupling of the atmosphere and ocean is very sensitive to the amount of downward longwave radiation received at the ocean surface, while Ebert and Curry (1993) noted an extreme sensitivity of simulated sea ice thickness to changes in downward shortwave and longwave fluxes. In the present study we use the information contained in both surface and top-of-atmosphere (TOA) observations to assess the radiative fluxes simulated in the ECHAM5 GCM.

Radiative fluxes in previous versions of the ECHAM 
model suite have been evaluated in a series of papers from both a satellite and surface point of view (Roeckner et al. 1992, 1996; Chen and Roeckner 1996; Wild et al. 1995a,b, 1998, 2001). The purpose of the present study is to document the performance of the most recent version, ECHAM5, and its improvement compared to previous models with respect to radiation. In the precursor version, ECHAM4, despite considerable improvements in the radiation budget compared to ECHAM3, a number of shortcomings were still present. In the shortwave, the radiation scheme used in ECHAM4 (Fouquart and Bonnel 1980) was shown to perform accurately under clear-sky conditions but introduced spurious absorption in cloudy skies (Chen and Roeckner 1996; Wild et al. 1998). This has been related to the coarse spectral resolution of the shortwave radiation scheme with only two bands, as indicated in stand-alone radiation calculations with varying band resolution (Wild et al. 1998). In ECHAM5, the number of shortwave bands is increased from two to four, the minimum resolution required to avoid spurious cloud absorption. Biases in the longwave fluxes at the surface in previous ECHAM versions have been documented in Wild et al. (2001). ECHAM5 uses a new longwave radiation code, which will be shown to remove some of these biases.

This paper is structured as follows. After a brief introduction into models and observational data used in this study (section 2), the TOA fluxes are evaluated in section 3. The surface fluxes are assessed in section 4 , and the main findings are discussed in section 5 .

\section{Model and observational data}

ECHAM5 is described in detail in Roeckner et al. (2003). The precursor versions ECHAM3 and ECHAM4 are described in Roeckner et al. (1992) and Roeckner et al. (1996), respectively. In the longwave, ECHAM5 includes a new radiation code [Rapid Radiative Transfer Model (RRTM)] developed by Mlawer et al. (1997). It is based on the two-stream approximation instead of the emissivity method applied in ECHAM4 (Morcrette et al. 1986). The RRTM code is used in the European Centre for Medium-Range Forecasts (ECMWF) operational forecasting system (Morcrette 2002a,b) and has also been tested in the National Center for Atmospheric Research (NCAR) Community Climate Model (CCM3) (Iacono et al. 2000). The solar radiation code is the same as in ECHAM4 (Fouquart and Bonnel 1980) with two modifications. First, the number of spectral bands has been doubled from two to four, with two additional bands in the nearinfrared part of the spectrum. Second, the computation of transmissivities and reflectivities across a vertical column is now split into two separate calculations for the cloud-free section and the cloudy section. The ECHAM5 data are obtained from a 15-yr Atmospheric Model Intercomparison Project (AMIP) simulation for the time period 1979-93 at T106L31 resolution using observed monthly sea surface temperatures and sea ice concentrations as lower boundary forcing.

The satellite climatologies of the TOA radiative fluxes are taken from ERBE (Barkstrom et al. 1990), averaged over the period $1985-89$. The resolution is $2.5^{\circ} \times 2.5^{\circ}$. Uncertainties in the monthly averaged scanner data are estimated within $\pm 5 \mathrm{~W} \mathrm{~m}^{-2}$. The observational data for the assessment of the surface fluxes have been retrieved from two databases hosted by the Swiss Federal Institute of Technology: the Global Energy Balance Archive (GEBA: Gilgen and Ohmura 1999) and the database of the Baseline Surface Radiation Network (BSRN: Ohmura et al. 1998). GEBA is a database for the worldwide measured energy fluxes at the earth's surface and contains monthly mean values of various surface energy balance components. This database currently possesses 220000 monthly mean fluxes for more than 2000 sites and has been used in a number of studies to assess model- and satellite-derived estimates of surface energy fluxes. Gilgen et al. (1998) estimated the relative random error (root-mean-square error/mean) of the incoming shortwave radiation values in the GEBA at $5 \%$ for the monthly means and $2 \%$ for annual means. The database of the BSRN includes measurements at high temporal resolution (minute values) with the highest possible accuracy at selected sites in different climate regions. Additionally, synoptic measurements and upper air soundings from radiosondes are stored at these sites, which constitute an ideal test bed for the validation of radiation codes.

\section{TOA fluxes}

Global and annual mean TOA radiative fluxes and cloud forcings are listed in the upper part of Table 1. In all model versions the simulated fluxes are within the uncertainty range of the satellite data (about $\pm 5 \mathrm{~W}$ $\mathrm{m}^{-2}$ ). There is a spurious imbalance in TOA net radiation (absorbed - emitted) of $+6 \mathrm{~W} \mathrm{~m}^{-2}$ in the ERBE data and $+3 \mathrm{~W} \mathrm{~m}^{-2}$ in the International Satellite Cloud Climatology Project (ISCCP) data. In the ECHAM5 model, on the other hand, cloud parameters have been tuned for achieving a balance close to zero in the longterm mean (Roeckner et al. 2006). At the surface the global mean reference estimates differ by an even larger amount, that is, $\pm 7-10 \mathrm{~W} \mathrm{~m}^{-2}$ for the solar components and $\pm 15-20 \mathrm{~W} \mathrm{~m}^{-2}$ for the terrestrial compo- 
TABLE 1. Global mean radiation budgets and cloud forcings at the TOA, surface, and atmosphere in the model versions ECHAM3, ECHAM4, and ECHAM5 together with reference estimates (sources provided as footnotes). Horizontal resolution is T106 and vertical resolution is L19, except for ECHAM5 (L31).

\begin{tabular}{|c|c|c|c|c|}
\hline & ECHAM3 & ECHAM4 & ECHAM5 & Reference estimates \\
\hline \multicolumn{5}{|l|}{ Top of atmosphere $\left(\mathrm{W} \mathrm{m}^{-2}\right)$ : } \\
\hline SW absorbed all-sky & 235 & 237 & 235 & $240,{ }^{\mathrm{a}} 236,{ }^{\mathrm{b}} 235^{\mathrm{e}}$ \\
\hline SW absorbed clear-sky & 284 & 286 & 287 & $288,{ }^{\mathrm{a}} 286^{\mathrm{b}}$ \\
\hline SW cloud forcing & -49 & -49 & -52 & $-48,{ }^{\mathrm{a}}-50^{\mathrm{b}}$ \\
\hline LW emitted all-sky & 233 & 235 & 235 & $234,{ }^{\mathrm{a}} 233{ }^{\mathrm{b}} 235^{\mathrm{e}}$ \\
\hline LW emitted clear-sky & 262 & 263 & 262 & $264,{ }^{\mathrm{a}} 258^{\mathrm{b}}$ \\
\hline LW cloud forcing & 29 & 28 & 27 & $30,{ }^{\mathrm{a}} 25^{\mathrm{b}}$ \\
\hline \multicolumn{5}{|l|}{ Atmosphere $\left(\mathrm{W} \mathrm{m}^{-2}\right)$ : } \\
\hline SW absorbed all-sky & 71 & 90 & 76 & $71,{ }^{\mathrm{b}} 85^{\mathrm{c}}$ \\
\hline SW absorbed clear-sky & 63 & 72 & 72 & $68^{\mathrm{b}} 72^{\mathrm{c}}$ \\
\hline SW cloud forcing & 8 & 18 & 4 & $3^{\mathrm{b}}$ \\
\hline \multicolumn{5}{|l|}{ Surface $\left(\mathrm{W} \mathrm{m}^{-2}\right)$ : } \\
\hline SW incoming all-sky & 189 & 170 & 184 & $189,^{\mathrm{b}} 170^{\mathrm{f}}$ \\
\hline SW absorbed all-sky & 164 & 147 & 159 & $165^{\mathrm{b}} 154,^{\mathrm{c}} 161,{ }^{\mathrm{d}} 168,{ }^{\mathrm{e}} 142^{\mathrm{f}}$ \\
\hline SW absorbed clear-sky & 222 & 214 & 214 & $217, \mathrm{~b} 215^{\mathrm{c}}$ \\
\hline SW cloud forcing & -58 & -67 & -55 & $-52^{\mathrm{b}}$ \\
\hline LW incoming all-sky & 334 & 344 & 344 & $343,^{\mathrm{b}} 345,^{\mathrm{c}} 348^{\mathrm{d}}$ \\
\hline LW incoming clear-sky & 311 & 323 & 318 & $313^{\mathrm{b}} 321^{\mathrm{c}}$ \\
\hline LW upward & 397 & 397 & 398 & $393^{\mathrm{b}}$ \\
\hline Net LW all-sky & -63 & -53 & -54 & $-50^{\mathrm{b}}$ \\
\hline LW cloud forcing & 23 & 21 & 26 & $30^{\mathrm{b}}$ \\
\hline Surface net radiation & 101 & 94 & 105 & $115,^{\mathrm{b}} 103^{\mathrm{c}}$ \\
\hline
\end{tabular}

a ERBE data (Barkstrom et al. 1990).

b ISCCP data (Raschke et al. 2005).

${ }^{c}$ Wild et al. (1998).

d Gupta et al. (1999).

${ }^{\mathrm{e}}$ Kiehl and Trenberth (1997).

${ }^{\mathrm{f}}$ Ohmura and Gilgen (1993).

nents (Raschke et al. 2005). All of the ECHAM5 simulated fluxes are within this relatively large error range. The same applies for the atmospheric fluxes, which are obtained as a residual between the TOA fluxes and the surface fluxes, respectively.

\section{a. Zonal means}

Figure 1 shows simulated (ECHAM5) and observed (ERBE) meridional profiles of zonal-mean longwave radiative fluxes for the December-February (DJF) and June-August (JJA) seasons, respectively. High latitudes (poleward of $60^{\circ}$ ) are excluded from this comparison because the ERBE clear-sky fluxes are less reliable in polar regions due to the problems of scene identification in areas covered with snow or ice. The simulated clear-sky fluxes (upper pair of lines in Figs. $1 \mathrm{a}, \mathrm{b})$ are generally close to the respective ERBE estimates, though slightly smaller. This is most evident around $10^{\circ} \mathrm{N}$ during the JJA season where the simulated outgoing longwave radiation (OLR) is about $8 \mathrm{~W}$ $\mathrm{m}^{-2}$ too low, which is consistent with the overestimated water vapor content in the Tropics [Hagemann et al. 2006, hereafter HAR, their Fig. 6). The differences in all-sky OLR (lower pair of lines in Figs. 1a,b) between model and ERBE are less systematic than those of the clear-sky OLR. The deviations are mostly within the error bars of ERBE. In general, this applies also to the longwave cloud forcing (LWCF: Figs. 1c,d). Larger deviations from ERBE are simulated in the DJF season around $10^{\circ} \mathrm{S}$ and $40^{\circ} \mathrm{N}$.

Figure 2 shows simulated (ECHAM5) and observed (ERBE) meridional profiles of zonal-mean albedo (Figs. 2a,b), shortwave cloud forcing (SWCF) (Figs. $2 \mathrm{c}, \mathrm{d})$ and net cloud forcing $(\mathrm{NCF}=\mathrm{SWCF}+\mathrm{LWCF})$ (Figs. 2e,f) for the DJF and JJA seasons, respectively. The simulated clear-sky albedo (lower pair of lines in Figs. 2a,b) is in good agreement with the ERBE estimates. As in ECHAM4 (Chen and Roeckner 1996), the largest differences are found in DJF. Between $30^{\circ}$ and $40^{\circ} \mathrm{N}$ the simulated clear-sky albedo is somewhat high, whereas it is lower than observed between $40^{\circ}$ and $60^{\circ} \mathrm{N}$. It is unclear if this is due to deficiencies in simu- 

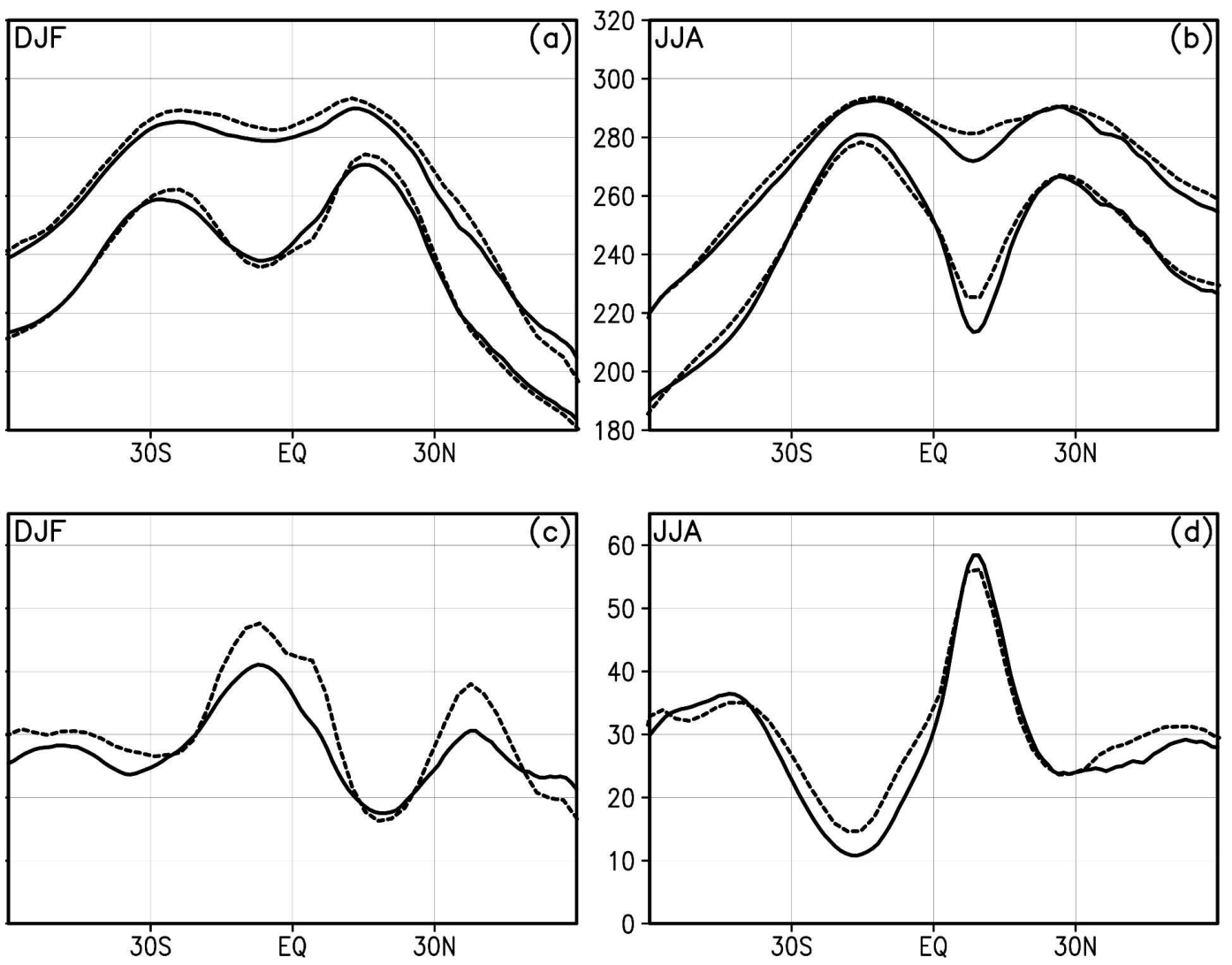

FIG. 1. Simulated (solid lines) and observed (ERBE, dashed lines) zonal mean radiative fluxes for DJF and JJA, respectively: (a), (b) outgoing longwave radiation (OLR), where the upper pair of curves refers to the clear-sky OLR and the lower pair to the all-sky OLR; (c), (d) longwave cloud forcing. Units: $\mathrm{W} \mathrm{m}^{-2}$.

lated snow cover and/or snow albedo or related to problems in ERBE clear-sky scene identification over snow-covered terrain. The meridional profiles of the planetary albedo (upper pair of lines in Figs. 2a,b) are well captured in both seasons, but the simulated values are systematically higher than observed. As noted above, this is a result of model tuning with the aim of achieving a global, annual balance between absorbed shortwave and emitted longwave radiation. As for the OLR (Fig. 1b), the largest differences between simulated and observed planetary albedo are found in JJA around $10^{\circ} \mathrm{N}$. However, unlike the OLR with the error being caused by too efficient trapping of clear-sky longwave radiation, the overestimated planetary albedo is caused solely by the SWCF, which is too high by about $20 \mathrm{~W} \mathrm{~m}^{-2}$ (Fig. 2d). These errors in both clear-sky OLR and in planetary albedo indicate that the intertropical convergence zone (ITCZ) in JJA might be too pronounced in the model. The simulated SWCF profiles shown in Figs. 2c,d are generally in good agreement with ERBE data and mostly within the ERBE error bars. As noted above, larger deviations occur in the
ITCZ during JJA, and this is also reflected in the NCF (Figs. 2e,f). Except for a systematic shift to larger negative values due to both larger SWCF and smaller LWCF, the simulated NCF profiles are similar to those of ERBE. The largest deviations of about $-20 \mathrm{~W} \mathrm{~m}^{-2}$ occur near the equator, especially in JJA, but also near $60^{\circ} \mathrm{N}$ in JJA.

\section{b. Geographic distributions}

Figure 3 shows a comparison of simulated and observed OLR for the DJF season. The minima in the Tropics (OLR $<220 \mathrm{~W} \mathrm{~m}^{-2}$ ) are closely connected with the locations of deep convection in the west Pacific and Maritime Continent, in the Indian Ocean, in the South Pacific convergence zone (SPCZ), and in the Congo and Amazon River basins. Most of these features are well captured by the model, particularly those over tropical land areas. Over the Indian Ocean the OLR is somewhat lower than in ERBE, whereas it is higher over parts of the Maritime Continent. The dark areas in Fig. 3 (top and middle panels) indicate the relatively dry subtropical subsidence regions with OLR 

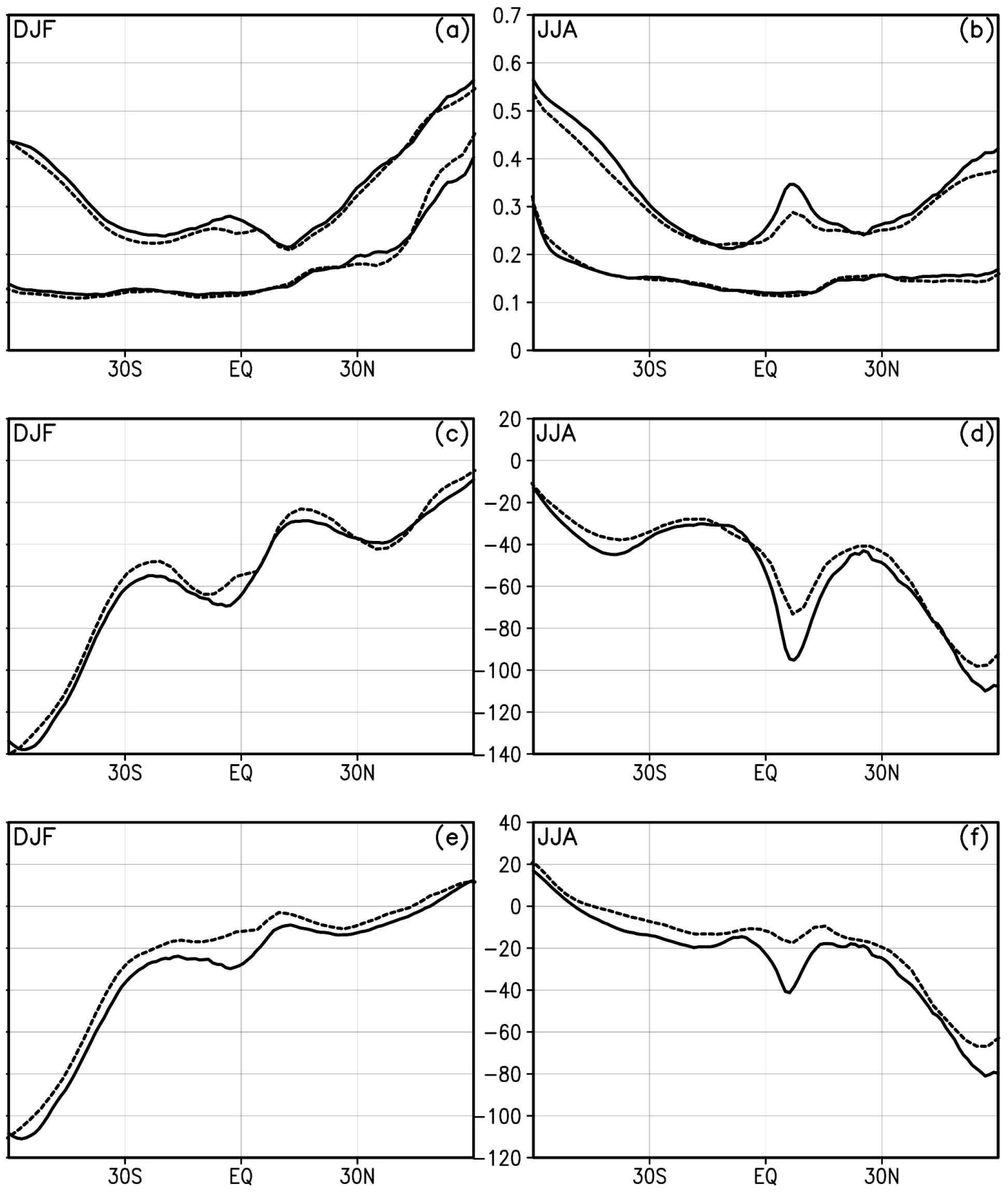

FIG. 2. Simulated (solid lines) and observed (ERBE, dashed lines) zonal mean albedo and cloud forcing for DJF and JJA, respectively: (a), (b) planetary albedo, where the upper pair of curves refers to the all-sky albedo and the lower pair to the clear-sky albedo; (c), (d) shortwave cloud forcing $\left(\mathrm{W} \mathrm{m}^{-2}\right)$; (e), (f) net (sum of longwave and shortwave) cloud forcing $\left(\mathrm{W} \mathrm{m}^{-2}\right)$.

exceeding $280 \mathrm{~W} \mathrm{~m}^{-2}$. All of the observed broad-scale features are captured in the simulation, but there are differences in the details (lower panel), especially at lower latitudes. The most prominent feature is the overestimation of the OLR, by up to $30 \mathrm{~W} \mathrm{~m}^{-2}$, over the Maritime Continent, collocated with a negative rainfall anomaly (cf. HAR, their Fig. 4).

In JJA (Fig. 4), the deviations from ERBE are some- what larger than in DJF. The subtropical subsidence zones are more extended than in ERBE, while the OLR is underestimated in convectively active regions (western and central Pacific, Gulf of Mexico, northern Indian Ocean). This combination of errors, which is consistent with the distribution of rainfall patterns [subtropics too dry and too much rain over the tropical oceans (HAR, their Fig. 5)], suggests that the convec- 

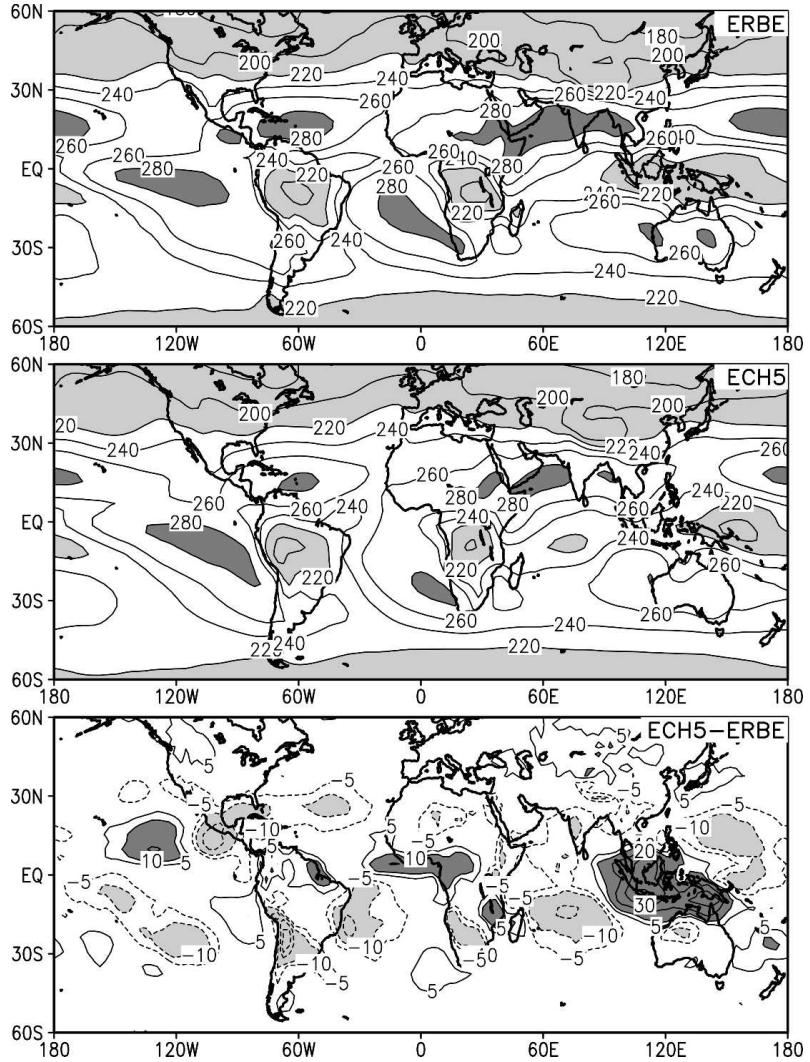

FIG. 3. Observed and simulated outgoing longwave radiation for DJF. Units: $\mathrm{W} \mathrm{m}^{-2}$. (top), (middle) Light shading for OLR < $220 \mathrm{~W} \mathrm{~m}^{-2}$, dark shading for OLR $>280 \mathrm{~W} \mathrm{~m}^{-2}$. (bottom) Light shading for negative errors $\left(<-10 \mathrm{~W} \mathrm{~m}^{-2}\right)$, dark shading for positive errors $\left(>10 \mathrm{~W} \mathrm{~m}^{-2}\right)$

tively driven circulations are too strong in these regions.

The simulated and observed patterns of DJF longwave cloud forcing (LWCF) are shown in Fig. 5. Large LWCF is indicative of extensive shields of cold cirrus clouds associated with deep convection (the Amazon and Congo River basins, the west Pacific warm pool region, and the SPCZ). The positions of these LWCF maxima are well captured by the model but the amplitudes are systematically too low, especially over the Maritime Continent. In the ERBE data, the ITCZ in the Pacific and Atlantic Oceans is less pronounced, which indicates that high clouds are not abundant in the DJF season. In the model, the LWCF in the ITCZ region is systematically underestimated, although the rainfall pattern is realistic (cf. HAR, their Fig. 4). This suggests that convective clouds detrain their cloud water at lower (i.e., warmer) levels than in the real atmosphere. Note that the LWCF error pattern shown in Fig. 5 is very similar, except for sign, to the OLR error pattern (cf. Fig. 3), implying that the OLR errors are
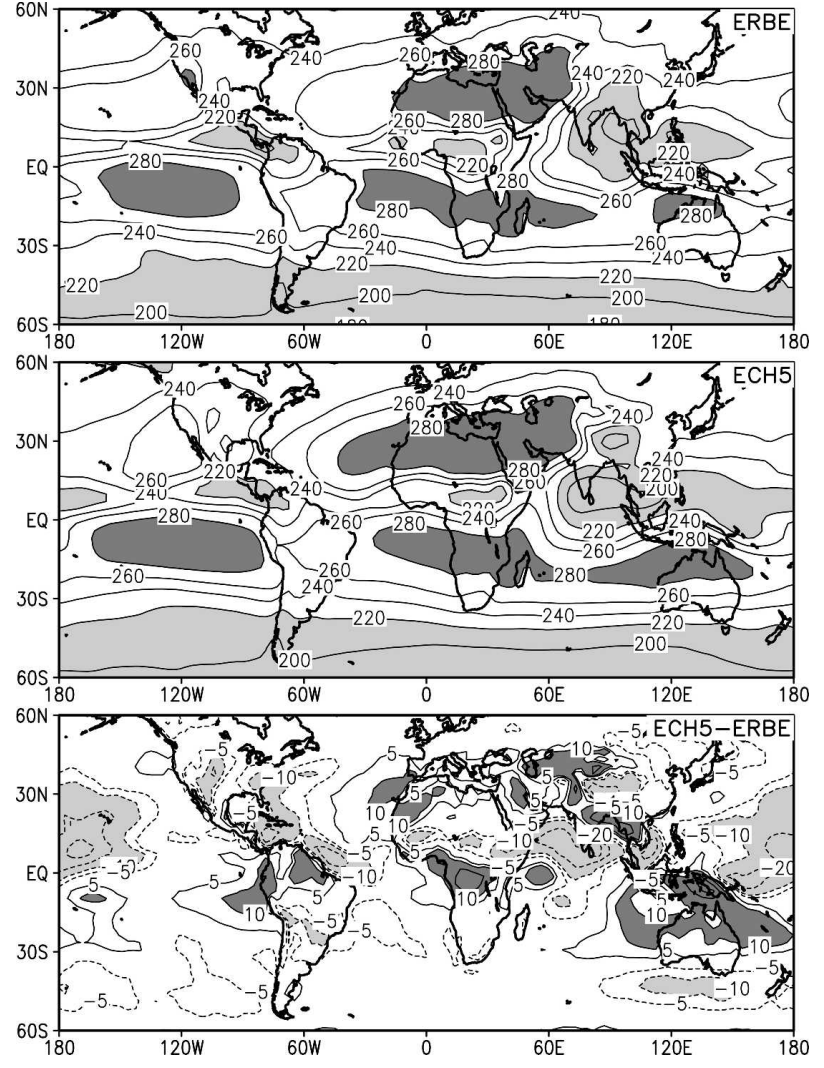

FIG. 4. As in Fig. 3, but for JJA.

predominantly due to errors in the three-dimensional distribution of high clouds and also, very likely, to errors in their optical properties.

In JJA (Fig. 6), the LWCF patterns advance northward and the ITCZ becomes more pronounced, compared to the DJF season, in both the ERBE data and the ECHAM5 simulation. A marked seasonal variation can also be identified at midlatitudes where the storm tracks are becoming weaker (stronger) in the summer (winter) hemisphere. Negative biases can be found predominantly over low-latitude land areas (the northern part of South America, the Congo River basin, and the Asian monsoon region), whereas an extensive positive anomaly of more than $10 \mathrm{~W} \mathrm{~m}^{-2}$ is simulated in the central Pacific and also in the northern part of the Indian Ocean. Most of these biases are consistent with the respective rainfall anomalies (cf. HAR, their Fig. 5). An exception is the Asian monsoon region where the rainfall bias is positive while the LWCF bias is negative. This discrepancy suggests an underestimation of the cloud top height and/or high clouds being optically too thin. As in DJF the LWCF error pattern is very similar, except for sign, to the OLR error (cf. Fig. 4).

Figure 7 shows a comparison between simulated and observed shortwave cloud forcing in the DJF season. In 

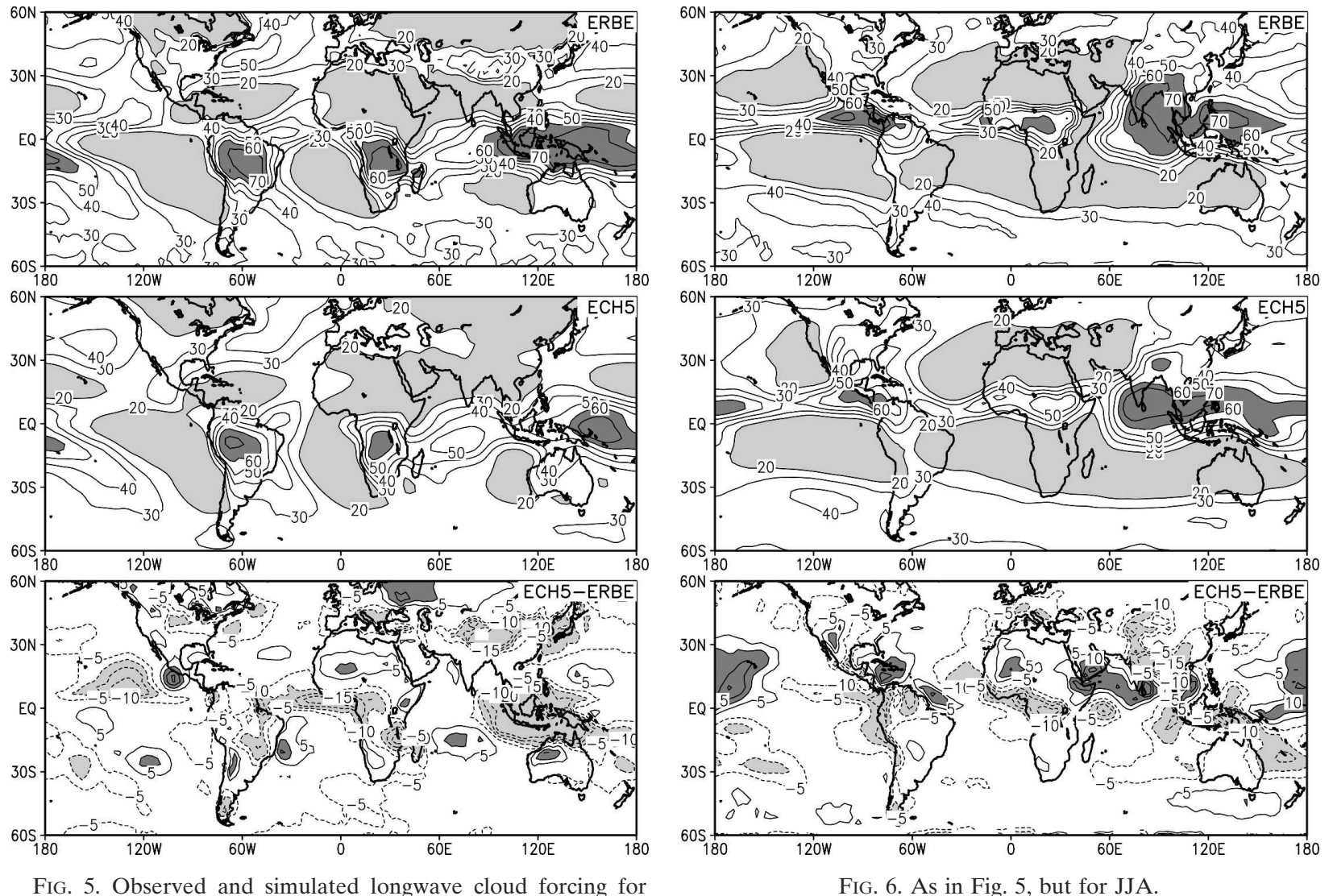

FIG. 5. Observed and simulated longwave cloud forcing for DJF. Units: $\mathrm{W} \mathrm{m}^{-2}$. (top), (middle) Light shading for LWCF $<20$ $\mathrm{W} \mathrm{m}{ }^{-2}$, dark shading for $\mathrm{LWCF}>60 \mathrm{~W} \mathrm{~m}^{-2}$. (bottom) Light shading for negative errors $\left(<-10 \mathrm{~W} \mathrm{~m}^{-2}\right)$, dark shading for positive errors $\left(>10 \mathrm{~W} \mathrm{~m}^{-2}\right)$

contrast to LWCF, the SWCF depends not only on the amount and optical properties of the clouds but also on the solar irradiance. Therefore, the highest SWCF is found in areas of extensive cloudiness in the respective summer hemisphere as, for example, in DJF over the Southern Ocean. The marked increase of SWCF from lower to higher latitudes in the Southern Hemisphere is well captured in the simulation. The errors at midlatitudes, poleward of about $30^{\circ}$ in both hemispheres, are much smaller than those at lower latitudes. The maxima over the tropical continents are systematically too high, by more than $20 \mathrm{~W} \mathrm{~m}^{-2}$, whereas the stratocumulus regions off the west coasts of South America and southern Africa are less extended than in the ERBE data, which leads to model biases of up to $-40 \mathrm{~W} \mathrm{~m}^{-2}$ in the east Pacific. The negative SWCF bias over the Maritime Continent, together with similar biases of LWCF (cf. Fig. 5) and rainfall (cf. HAR, their Fig. 4), suggests that the main source of error is a weak large-scale forcing in this region.

The simulated SWCF patterns in JJA (Fig. 8) are

similar to those of ERBE but the amplitude is systematically high (see also Fig. 2). This applies not only to the ITCZ in the Pacific and Atlantic Oceans but also to central Africa and India. Additionally, there is a spurious maximum over Tibet/western China. Over the North Pacific and North Atlantic Oceans the simulated SWCF is also higher than observed. The close correspondence between overestimated SWCF and rainfall (cf. HAR, their Fig. 5) suggests that the dynamical and/ or convective forcing is too strong in these regions. Local SWCF maxima in the ERBE data off the coasts of California, Peru, North Africa, and Angola are indicative of stratocumulus clouds forming over relatively cold water. These features are also captured in the model simulation although, similar to DJF, the SWCF is underestimated in most of these regions.

The broad-scale pattern of the net cloud forcing $(\mathrm{NCF}=\mathrm{LWCF}-\mathrm{SWCF}$ according to the sign convention in Figs. 7 and 8) shown in Fig. 9 for the DJF season is well captured by the model. Small positive values can be found in both the model and ERBE data in parts of the winter hemisphere, whereas large negative values $\left(<-100 \mathrm{~W} \mathrm{~m}^{-2}\right)$ are simulated and observed over parts of the Southern Ocean. Negative biases of up to $-40 \mathrm{~W} \mathrm{~m}^{-2}$ can be found over the tropical continents 

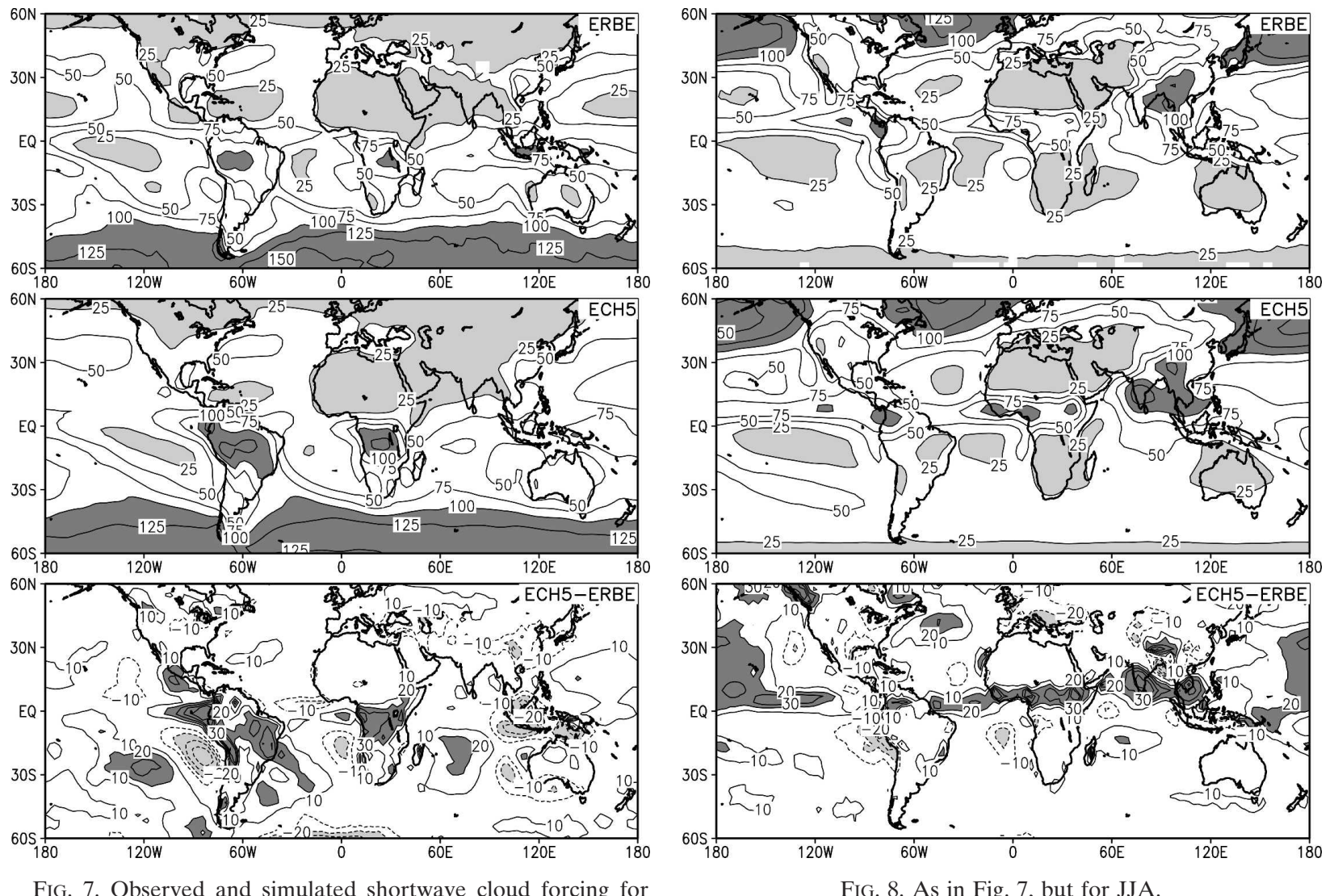

FIG. 7. Observed and simulated shortwave cloud forcing for DJF. Note that positive values denote shortwave cloud radiative cooling. Units: $\mathrm{W} \mathrm{m}^{-2}$. (top), (middle) Light shading for SWCF < $25 \mathrm{~W} \mathrm{~m}^{-2}$, dark shading for SWCF $>100 \mathrm{~W} \mathrm{~m}^{-2}$. (bottom) Light shading for negative errors $\left(<-20 \mathrm{~W} \mathrm{~m}^{-2}\right)$, dark shading for positive errors $\left(>20 \mathrm{~W} \mathrm{~m}^{-2}\right)$

(South America, Africa) and also in the eastern parts of the equatorial Pacific and Atlantic Oceans. These biases are predominantly due to the overestimated SWCF in these regions and, to a lesser extent, to the underestimated LWCF. Consistent with the lack of SWCF in the stratocumulus regions off the coasts of Peru, Angola, and Western Australia, the NCF biases in these regions are positive (up to $40 \mathrm{~W} \mathrm{~m}^{-2}$ along the Peruvian coast).

Most of these errors are also apparent in Fig. 10, which shows the simulated and observed NCF in the JJA season. Over tropical land areas (northern part of South America, central Africa, India, Southeast Asia), along the ITCZ in the Pacific and Atlantic Oceans, and also in the North Pacific and North Atlantic, the simulated NCF is too negative compared to ERBE. On the other hand, the marine stratocumulus regimes are better captured than in the DJF season. As in DJF, the NCF over the Sahara Desert and the Arabian peninsula is slightly positive in both the simulation and the ERBE

data. This net cloud radiative warming of the surfaceatmosphere system is caused by a lack of low-level water clouds $(\mathrm{SWCF} \approx 0)$ in conjunction with a sporadic occurrence of cirrus clouds (LWCF $>0$ ). Noteworthy are the small NCF values in the tropical west Pacific and in the Indian Ocean (see also Fig. 9). These are regions where optically thick cirrus clouds and also cumulus congestus clouds contribute to large SWCF and LWCF with partial compensation because of different signs. This near cancellation between SWCF and LWCF, which is typical for the whole Tropics (Kiehl 1994), is not simulated over the tropical continents where the LWCF is generally too small and the SWCF is systematically too large. This problem could be an indication for an incorrect vertical cloud distribution with overestimated low and middle water clouds and underestimated cirrus clouds.

\section{Surface fluxes}

We now turn our focus on the distribution of the radiative fluxes at the surface, which is critical for the coupling of the atmospheric model to the land surface, biosphere, cryosphere, and ocean model components in the framework of an earth system model. 

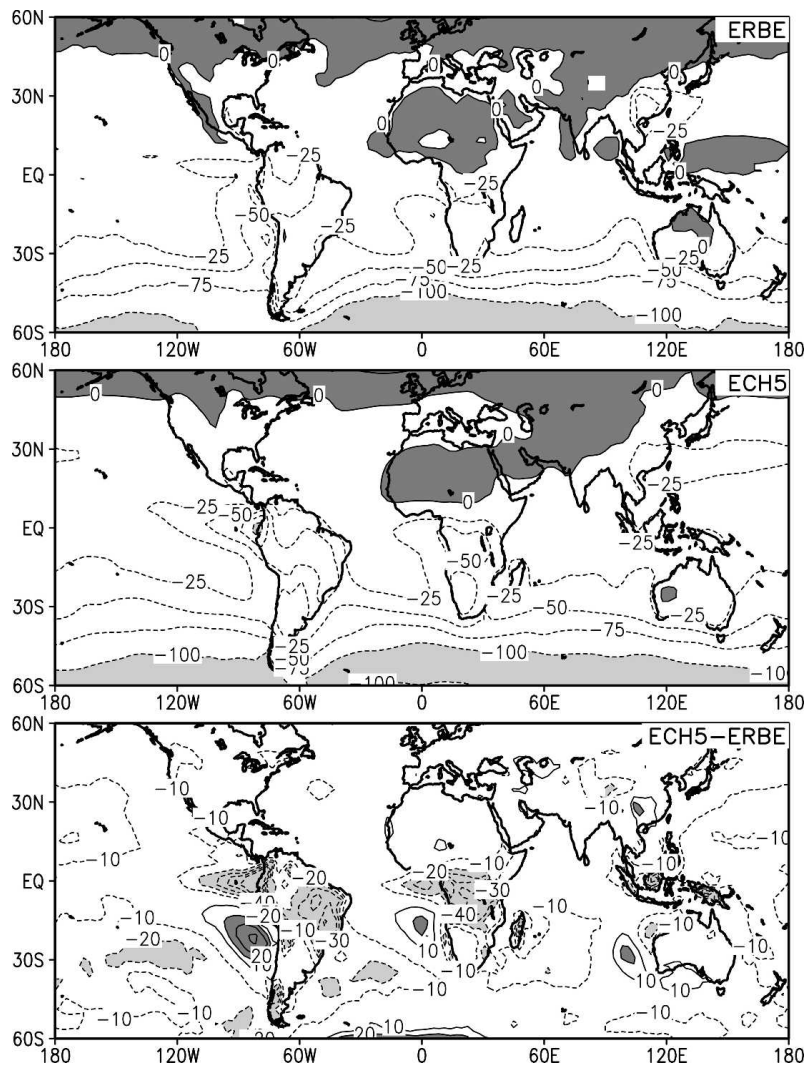

FIG. 9. Observed and simulated net cloud forcing for DJF (i.e., the difference between Figs. 5 and 7). Units: $\mathrm{W} \mathrm{m}^{-2}$. (top), (middle) Light shading for NCF $<-100 \mathrm{~W} \mathrm{~m}^{-2}$, dark shading for $\mathrm{NCF}>0 \mathrm{~W} \mathrm{~m}^{-2}$. (bottom) Light shading for negative errors $\left(<-20 \mathrm{Wm}^{-2}\right)$, dark shading for positive errors $\left(>20 \mathrm{Wm}^{-2}\right)$

Global annual mean values of the various radiative fluxes in the three ECHAM versions are given in Table 1. Significant differences can be noted between ECHAM5 and its precursor versions, particularly with respect to surface and atmospheric shortwave absorption. Here ECHAM5 lies between ECHAM3 and ECHAM4. As noted earlier, all of the ECHAM5 simulated fluxes are within the range of the reference estimates. For a more rigorous assessment of the modelcalculated surface fluxes, a comparison with the comprehensive set of direct observations described in section 2 is performed in the following.

\section{a. Shortwave fluxes at the surface and in the atmosphere}

\section{1) Comparison with collocated GEBA AND ERBE OBSERVATIONS}

For the assessment of the shortwave fluxes with direct observations, 720 observation sites with multiyear records of downward shortwave radiation were chosen
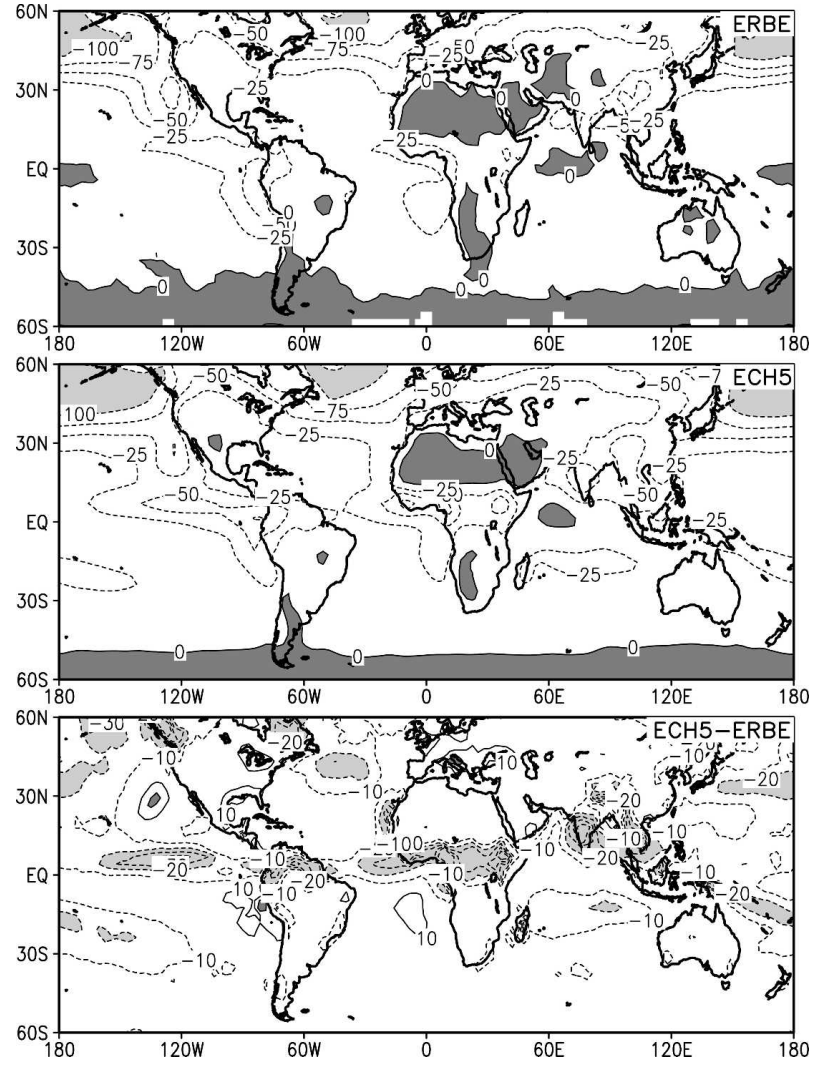

FIG. 10. As in Fig. 9, but for JJA.

from GEBA (Fig. 11). For the comparison of GCM fluxes with those observed, the model data were interpolated to the measurement sites using the four surrounding grid points weighted by their inverse spherical distance. Ocean grid points, which may surround the sites, have not been taken into account. The high horizontal resolution of the models $\left(\sim 1.1^{\circ}\right)$ facilitates a comparison with point measurements compared to coarser-resolution GCMs, due to more realistic coastlines and topography. This prevents, for example, observation sites on land from being located in ocean areas in the model and reduces the altitudinal differences between the model grid points and the observational sites in nonflat terrain. This is particularly important for the longwave flux comparison since these fluxes show significant altitudinal gradients. However, in general, the overall biases are not overly sensitive to resolution (Wild et al. 1995a,b).

The representativeness of a point measurement for a GCM grid box is a critical issue. Gilgen et al. (1998) estimated, based on $2.5^{\circ} \times 2.5^{\circ}$ grid boxes, that the difference of shortwave irradiance yearly means measured at different stations within a grid box is less than $5 \%$ of the box mean, and the interannual variability is approximately $4 \%$ of the cell mean. The high-resolu- 
(a)

Sites measuring downward shortwave radiation

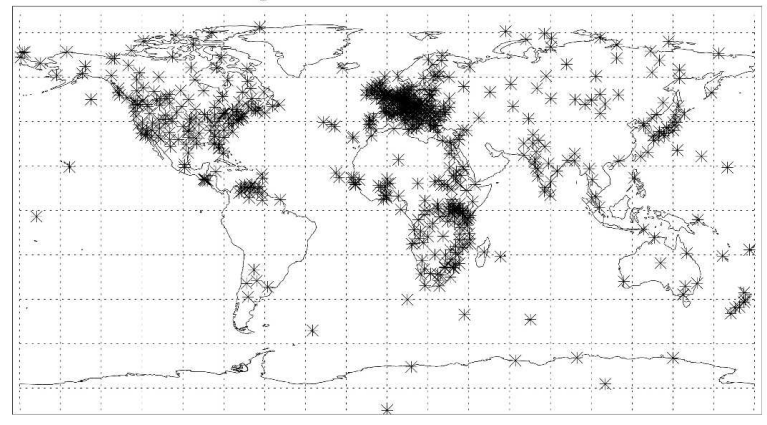

(b)

\section{Sites measuring downward longwave radiation}

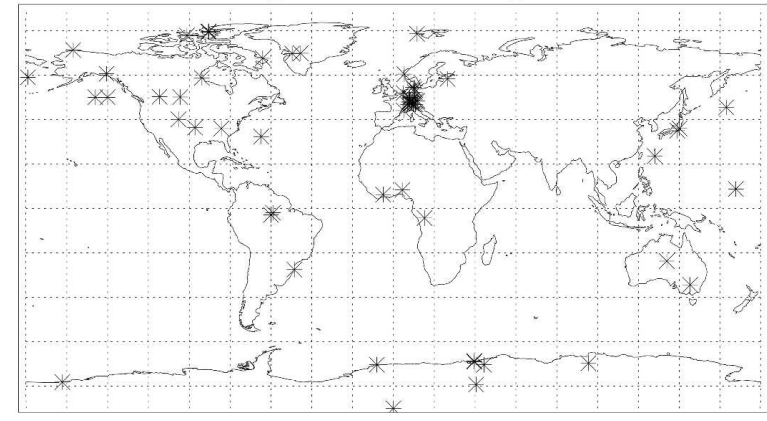

FIG. 11. Global distribution of the (a) 720 observation sites with downward shortwave radiation measurements from GEBA and (b) 45 observation sites with downward longwave radiation measurements from GEBA and BSRN used in this study.

tion model grids $\left(1.1^{\circ}\right)$ and the long-term nature of the observational records used in this study ensure that these estimates are upper limits for the temporal and spatial sampling errors caused by subgrid variability. Li et al. (2005) performed a detailed analysis of the sampling error when using point measurement to represent GCM grid boxes and conclude that, for computing gridmean surface solar irradiance, there is no need for an overly dense network of observation stations.

To obtain a reference dataset for the assessment of the GCM absorbed shortwave radiation at the surface, the observed values of the incoming shortwave radiation from GEBA have been weighted with the collocated values of a surface albedo climatology provided in the Surface Radiation Budget (SRB) Project (Darnell et al. 1992).

The differences between the absorbed surface solar radiation calculated in ECHAM3, ECHAM4, and ECHAM5 and observed estimates at the 720 sites are shown in the bottom panel of Fig. 12. The differences have been averaged over the sites located within latitudinal belts of $5^{\circ}$. Significant differences between ECHAM3, ECHAM4, and ECHAM5 are evident. In ECHAM3, too much solar energy is absorbed at the surface, particularly in low latitudes, a typical feature of GCMs and reanalyses (Wild et al. 1995a,b; Wild 2001, 2005). On the other hand, the absorption at the surface in ECHAM4 is in much better agreement with observations but slightly too low. ECHAM5 shows a somewhat higher surface absorption (cf. Table 1), thereby minimizing the bias compared to the observations.

Differences between the annual mean modelcalculated net shortwave fluxes at the TOA and the ERBE fluxes above the station sites are shown in the top panel of Fig. 12, again averaged over the sites in the $5^{\circ}$ latitude belts. The agreement between the models is better than at the surface, which is not unexpected since the models are tuned to match their TOA fluxes with satellite values, at least on global mean scales. The differences between model-calculated atmospheric shortwave absorption and the observational estimates can then be determined as residuals of the net flux differences at the top of atmosphere and at the surface, respectively (Fig. 12b). Whereas ECHAM3 absorbs too little solar energy in the atmosphere, ECHAM4 is in much better agreement but somewhat overestimates the atmospheric shortwave absorption. Also with respect to the atmospheric absorption, ECHAM5 shows the smallest biases over most latitudes except at low latitudes, which is discussed in more detail in the next section.

This suggests that the partitioning of shortwave absorption between the atmosphere and the surface is improved in ECHAM5 compared to its precursor versions. In other words, ECHAM5 may distribute the total amount of solar energy more realistically within the climate systems than in many GCMs or even reanalyses (cf. Wild et al. 1998; Wild 2000, 2001, 2005).

\section{2) CleAr-SKY ABSORPTION}

In an earlier paper, Wild et al. (1998) presented evidence that the shortwave clear-sky fluxes at the surface in ECHAM4 are well simulated and superior to ECHAM3. This was based on a stand-alone validation of the ECHAM3 (Hense et al. 1982) and ECHAM4 (Fouquart and Bonnel 1980) radiation codes. This validation was performed for clear-sky situations using prescribed profiles of atmospheric temperature and humidity from radiosonde data as input, which allows a direct comparison with synchronous surface observations. ECHAM5 uses the same radiation scheme as ECHAM4, except that the number of spectral bands in the shortwave is increased from two to four and separate calculations of transmissivity and reflectivity in the 

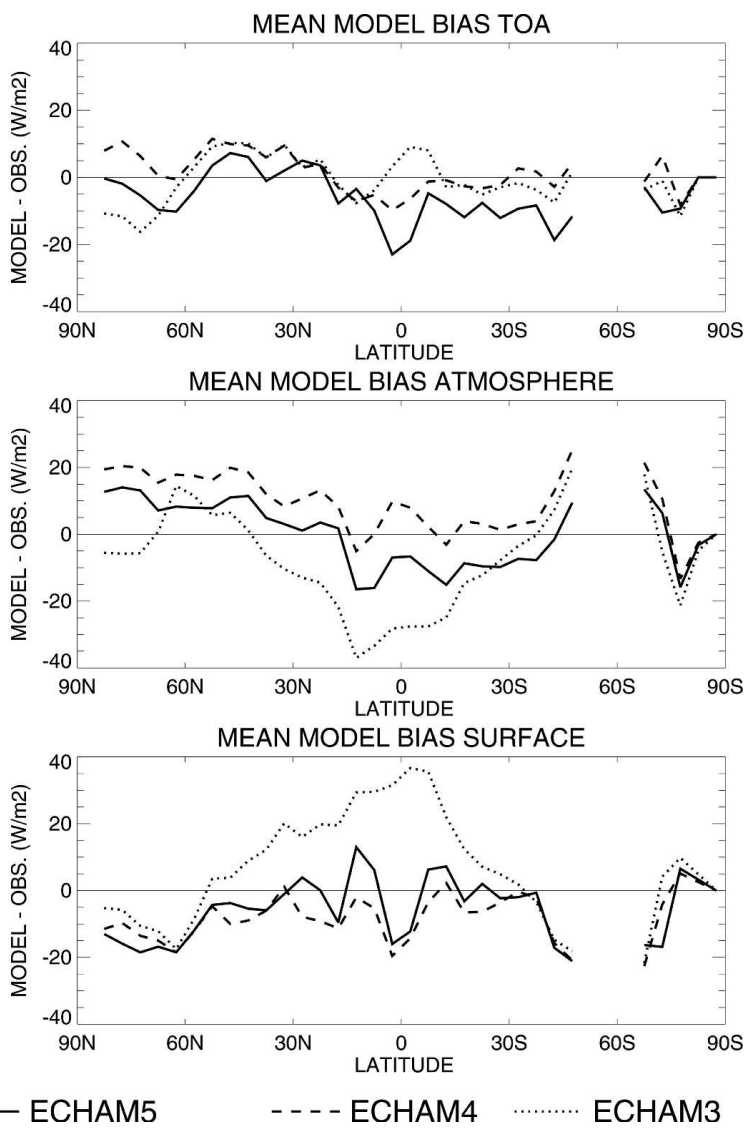

FIG. 12. Mean model bias of shortwave absorption (top) in the total surface/atmosphere system (TOA), (middle) within the atmosphere, and (bottom) at the surface at 720 observational sites as function of latitude for the three GCMs: ECHAM3, ECHAM4, and ECHAM5. Biases are averaged over sites within $5^{\circ}$ latitudinal bands. Surface observations are from GEBA and collocated TOA observations are from ERBE; units: $\mathrm{W} \mathrm{m}^{-2}$

cloud-free and cloudy part of a column are performed. Sensitivity studies by Wild et al. (1998) showed that the increase in band numbers has a negligible impact on the clear-sky fluxes (however, not so on the cloudy-sky fluxes as discussed below). This is also reflected in Table 1, which shows virtually the same shortwave clear-sky budgets for ECHAM4 and ECHAM5. The findings of the accurate performance of the shortwave radiation code under clear-sky conditions apply therefore to ECHAM5 as well. Recently, it has also become possible to assess the model-calculated clear-sky fluxes directly on climatological time scales. For this purpose, clear-sky climatologies for a number of observation sites are currently being constructed (Wild et al. 2006). Due to the high temporal resolution of insolation data provided by the BSRN stations, it is possible to separate clear-sky from cloudy-sky situations in the observational records, based on the algorithm of Long and
Ackerman (2000). These fluxes can then be aggregated into monthly and annual clear-sky climatologies representative for the respective BSRN sites (Wild et al. 2006). A first comparison of these observation-based estimates of long-term annual mean clear-sky fluxes with those calculated in ECHAM5 is given in Table 2 for a number of BSRN sites. A good agreement is apparent, with biases of only a few watts per square meter. This further indicates that the shortwave clearsky fluxes in ECHAM5 are well captured. The remaining biases may point to a slight tendency toward overestimation at some of the middle and low latitude sites, in line with the findings of Morcrette (2002b).

\section{3) Cloudy-Sky AND Aerosol ABSORPTION}

A measure of the overall effect of clouds on atmospheric absorption is the atmospheric cloud forcing, defined as the difference between the absorption of an atmosphere with clouds and the cloud-free atmosphere. Global annual mean values of atmospheric cloud forcing are given in Table 1. The atmospheric cloud forcing in ECHAM4 is distinctly higher than in ECHAM5. Previous studies showed that ECHAM4 simulates spurious cloud absorption due to the coarse resolution of the radiation code with only two bands in the shortwave (Chen and Roeckner 1996; Wild et al. 1998). This may contribute to the somewhat excessive atmospheric absorption when compared to the collocated surface and TOA observations seen in Fig. 12. Wild et al. (1998) performed sensitivity studies with the stand-alone radiation code and different numbers of spectral bands. The results showed that the cloudy-sky absorption is significantly reduced when increasing the number of spectral bands and that at least four bands are neces-

TABLE 2. Comparison of long-term annual mean shortwave clear-sky radiation at the surface determined at various BSRN sites using the Long and Ackerman (2000) algorithm with those from ECHAM5.

\begin{tabular}{lcc}
\hline \multicolumn{1}{c}{ Station } & ECHAM5 & Observed \\
\hline Alice Springs & 294.8 & 291.4 \\
Florianopolis & 273.2 & 262.8 \\
Ny Alesund & 114.8 & 119.0 \\
von Neumayer & 148.3 & 147.2 \\
Tateno & 252.0 & 254.4 \\
Syowa & 154.2 & 154.3 \\
Barrow & 136.0 & 137.2 \\
Boulder & 248.2 & 249.8 \\
Bermuda & 255.0 & 255.7 \\
Kwajalein & 300.8 & 297.3 \\
Billings & 246.2 & 249.6 \\
Manus & 304.8 & 298.3 \\
Nauru & 304.5 & 301.5 \\
\hline
\end{tabular}


sary to avoid spurious cloud absorption. Increasing the bands from two to four resulted in a reduction of atmospheric absorption of $15 \%$, equivalent to $13.5 \mathrm{~W}$ $\mathrm{m}^{-2}$ of the ECHAM4 global mean atmospheric absorption of $90 \mathrm{~W} \mathrm{~m}^{-2}$ (cf. Table 2). ECHAM5, which uses the four-band model, shows a reduction of atmospheric absorption of $13 \mathrm{~W} \mathrm{~m}^{-2}$ compared to ECHAM4, in line with the stand-alone sensitivity study mentioned above. This indicates that the more realistic four-band resolution in the radiation scheme contributes to the reduction of atmospheric absorption in ECHAM5 compared to ECHAM4. This may favor the smaller biases in atmospheric absorption in ECHAM5, particularly at middle and high latitudes (cf. Fig. 12).

Atmospheric absorption in ECHAM5, when compared to the observational estimates, is still somewhat low at low latitudes (cf. Fig. 12, middle panel). A part of the remaining underestimation of atmospheric absorption in ECHAM5 may be related to the fact that the aerosol representation in all ECHAM models is fairly crude (Tanré et al. 1984). The lack of appropriate representation of absorbing aerosol can lead to significant seasonal biases as shown in a study based on ECHAM3 and other GCMs (Wild 1999). This is particularly the case in areas with large injections of absorbing aerosol into the atmosphere, such as with strong biomass burning. This is illustrated for the area of equatorial Africa where widespread biomass burning takes place regularly during the dry season. The area of equatorial Africa was chosen because this region has the highest density of surface observations among those affected by biomass burning. The distribution of the observational sites in equatorial Africa, which are available from GEBA, can be inferred from Fig. 11. For ECHAM3 it has been shown that the biases are particularly pronounced during the dry season when most of the vegetation fires occur (winter season: January north of the equator, July south of the equator) (Wild 1999).

Here we extend this study to include ECHAM4 and ECHAM5. To estimate the effects of aerosols from biomass burning, a discussion on the seasonal scale is necessary, since human-induced biomass burning is a very distinct seasonal phenomenon, being predominately practiced during the dry seasons as a tool to clear savannas and forests. This is reflected in the seasonal occurrence of fires in equatorial Africa, as shown for the four midseason months in Fig. 13, left-hand panels, based on data provided by the European Space Agency (ESA) World Fire Atlas (Arino and Melinotte 1998). In January, with the dry season to the north of the equator, fires are largely concentrated in the area between $5^{\circ} \mathrm{N}$ and $10^{\circ} \mathrm{N}$, while in July, with the dry season shifted to the Southern Hemisphere, the fire activity is domi- nant to the south of the equator, with a maximum concentration between $5^{\circ}$ and $15^{\circ} \mathrm{S}$. The fire activity is significantly less pronounced during Northern Hemispheric spring and autumn, that is, during the rainy seasons over equatorial Africa.

The model-calculated biases in atmospheric absorption over equatorial Africa in the four midseason months are displayed in the right-hand panels of Fig. 13. As before for the more global analysis, the observed shortwave absorption within the atmospheric column above the African sites is determined as the difference between the net shortwave flux at the TOA from ERBE and the net shortwave flux at the surface from GEBA. Biases are again displayed as a function of latitude by averaging the biases of the sites located within latitudinal bands of $5^{\circ}$. A total of 87 observation sites, located between $15^{\circ} \mathrm{N}$ and $15^{\circ} \mathrm{S}$ are included in the analysis. In January, all models show a significant peak underestimation of atmospheric absorption at the surface to the north of the equator, precisely at the latitudes of maximum fire activity in that season. The peak absorption bias is in ECHAM4 and ECHAM5, but reduced by about $20 \mathrm{~W} \mathrm{~m}^{-2}$ compared to ECHAM3. In July, the peak underestimation of shortwave absorption in the atmosphere is shifted to the south of the equator following the maximum fire activity, which now occurs in the Southern Hemisphere. This suggests that aerosols from biomass burning seem to have a significant influence on atmospheric shortwave absorption also in ECHAM4 and ECHAM5 since all ECHAM versions use the same aerosol climatology (Tanré et al. 1984). This aerosol climatology does not include biomassburning effects and thus causes significant biases in the simulated seasonal radiation budgets. Accordingly, during the periods with little fire activity (April, October) no such dominant peak can be found in the absorption biases. Still, substantial differences exist in the absorption biases between the different ECHAM models. This is particularly true for areas and seasons not strongly affected by absorbing aerosol, corresponding to the wet seasons with high cloudiness, that is, in April and October throughout equatorial Africa, in January south of the equator, and in July to the north of the equator. In these seasons and areas, the cloud effects are dominant. It is striking that ECHAM5 shows the smallest biases of the ECHAM models under these conditions. While the atmospheric absorption in ECHAM4 is significantly too high during the rainy seasons, in ECHAM3 it is significantly too low. ECHAM5, on the other hand, lies in between and is close to the observational estimates. The underestimated absorption in ECHAM3 has already been noted in Wild 
a) JANUARY

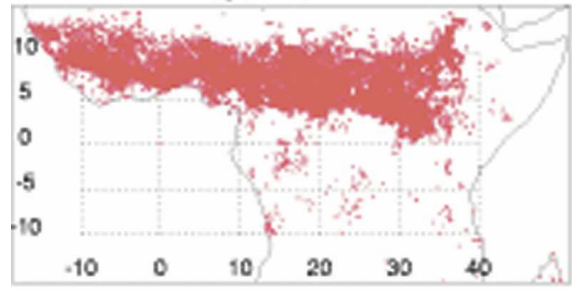

b) APRIL

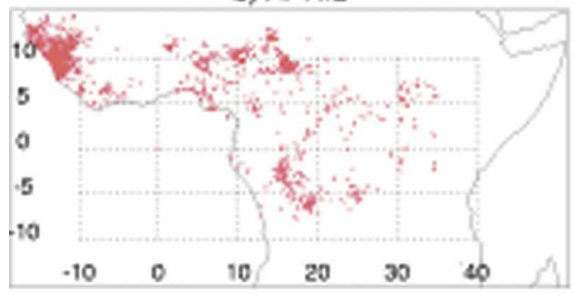

c) JULY

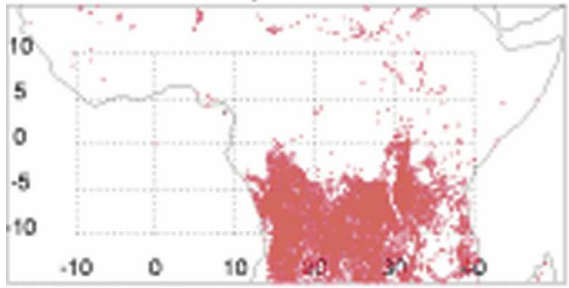

d) OCTOBER

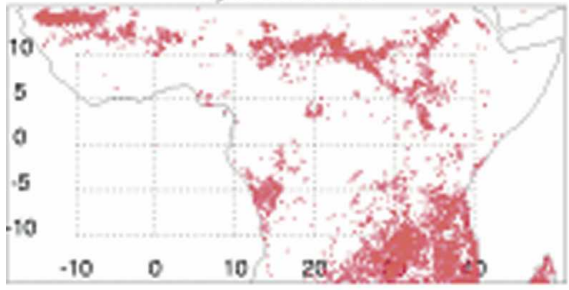

Vegetation fires
January

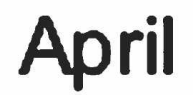

July

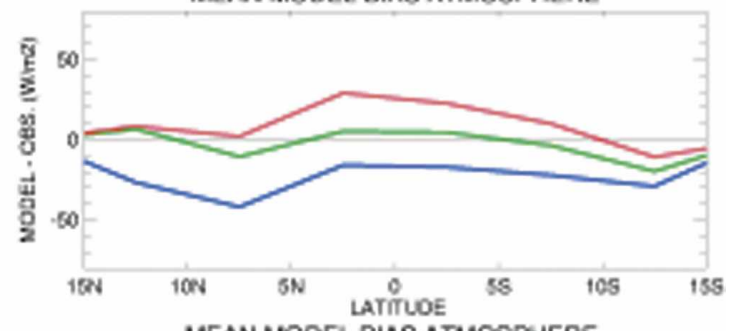

MEAN WOOEL BIAS ATMOSPHERE
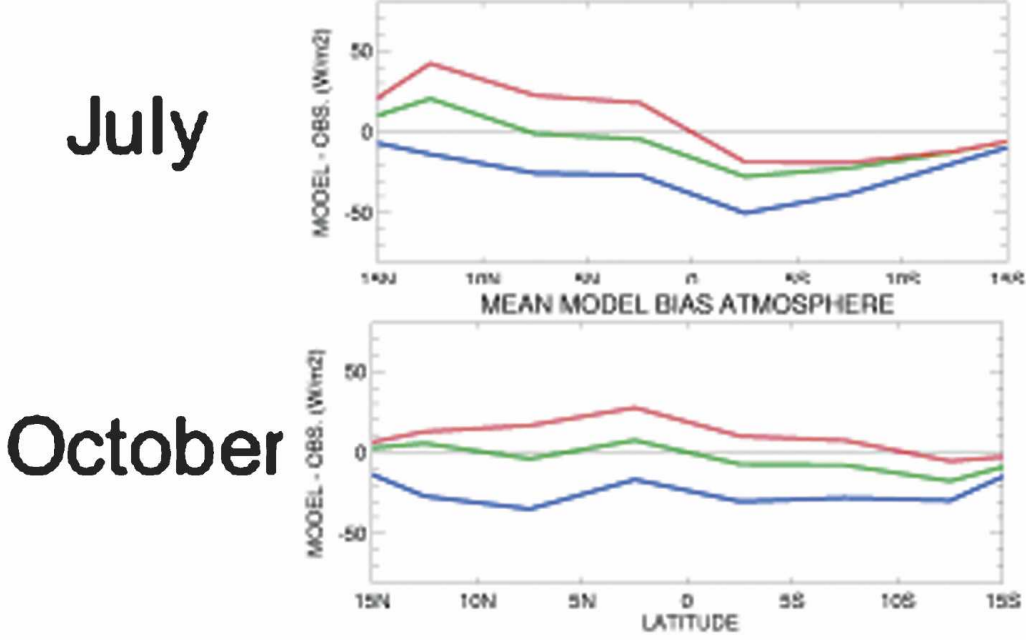

ECHAM5

FIG. 13. (left) Seasonal occurrence of vegetation fires in equatorial Africa as given in the ESA World Fire Atlas (Arino and Melinotte 1998) illustrated with the midseason months January 1993, April 1993, July 1993, and October 1993. (right) Bias of shortwave absorption in the atmosphere for the three model versions ECHAM3, ECHAM4, and ECHAM5 in the midseason months of January, April, July, September compared to collocated surface and satellite observations from GEBA/ERBE at sites in equatorial Africa as function of latitude. Biases are averaged over sites within $5^{\circ}$ latitudinal bands. Units: $\mathrm{W} \mathrm{m}^{-2}$.

(1999) and is related to the lack of clear-sky absorption. The clear-sky absorption in ECHAM3 is $9 \mathrm{~W} \mathrm{~m}^{-2}$ smaller than in ECHAM4/5 (cf. Table 1). The overestimation in ECHAM4 during the seasons in areas with substantial cloudiness, despite its accurate clear-sky absorption, is a further indication that the ECHAM4 cloud absorption is indeed too large. ECHAM5, with accurate clear-sky absorption and no more spurious cloud absorption, is then in close agreement with observations in areas and seasons unaffected by biomass burning. This again indicates that the reduced cloud absorption in ECHAM5 is more realistic than the one in ECHAM4. Note also that the absorption biases in ECHAM4 and ECHAM5 converge in January to the north of the equator and in July to the south of the equator, that is, during the dry seasons when cloud effects become irrelevant. This again underlines that the number of bands in the radiation scheme only affects the cloudy-sky fluxes but not the clear-sky fluxes.

To summarize, the increased number of bands and associated reduction in cloud absorption together with an accurate clear-sky absorption leads to a realistic atmospheric absorption in ECHAM5, except in those areas where aerosol absorption becomes important. 


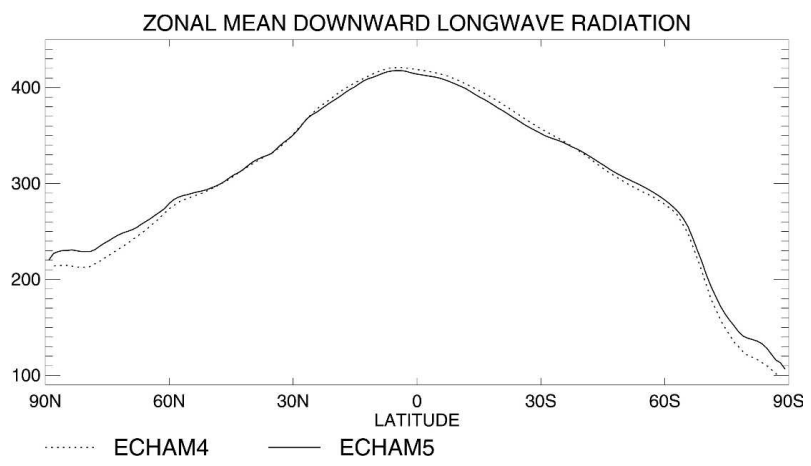

FIG. 14. Zonal annual mean downward longwave radiation at the surface calculated with ECHAM4 (dotted line) and ECHAM5 (solid line). Units: $\mathrm{W} \mathrm{m}^{-2}$.

\section{b. Surface longwave fluxes}

The exchange of energy between the atmosphere and ocean/land surfaces in the longwave is based on the thermal emission of the earth's surface and the atmospheric emission directed to the surface [incoming longwave radiation or downward longwave radiation (DLR)]. While the modeling of the thermal emission of the surface is straightforward according to the StefanBoltzmann law, the DLR has to be determined by comprehensive radiative transfer calculations, which take into account the complex radiative characteristics of the atmosphere. The focus of this assessment is therefore on DLR in the following.

In total, 45 observation sites are used for the assessment of the DLR: 26 sites from GEBA and 19 stations from BSRN. The worldwide distribution of these sites is given in Fig. 11. The current best estimate for the DLR measurement error is $\pm 10 \mathrm{~W} \mathrm{~m}^{-2}$ for the stations in GEBA based on the studies of DeLuisi et al. (1992) and Philipona et al. (1998), and references therein. The accuracy of DLR measurements according to BSRN standards is now about $2-3 \mathrm{~W} \mathrm{~m}^{-2}$ (Ohmura et al. 1998).

A correction has been applied whenever the elevation of the observation sites and the corresponding model grid points differ significantly, since DLR shows a strong dependence on altitude. The altitudinal correction applied here is based on the study of Wild et al. (1995b), with a height correction of $2.8 \mathrm{~W} \mathrm{~m}^{-2} / 100 \mathrm{~m}$. This height gradient was derived from the Swiss radiation network with three stations for DLR at different heights in the Alps. Due to the high resolution of the GCM used in this study, the height correction was marginal at most sites.

The earlier versions of ECHAM as well as different versions of the Hadley Centre model and the ECMWF reanalysis were analyzed in Wild et al. (2001). Substan- tial biases were found in the DLR of these GCMs with an underestimated DLR, particularly at high latitudes and for a cold and dry atmosphere, while a tendency for overestimation was found at low latitudes. This typically resulted in an excessive meridional gradient of DLR in GCMs (Wild et al. 2001). In ECHAM5 the longwave radiation code RRTM (Mlawer et al. 1997) was introduced. This code includes the CKD formulation of the water vapor continuum (Clough et al. 1989),
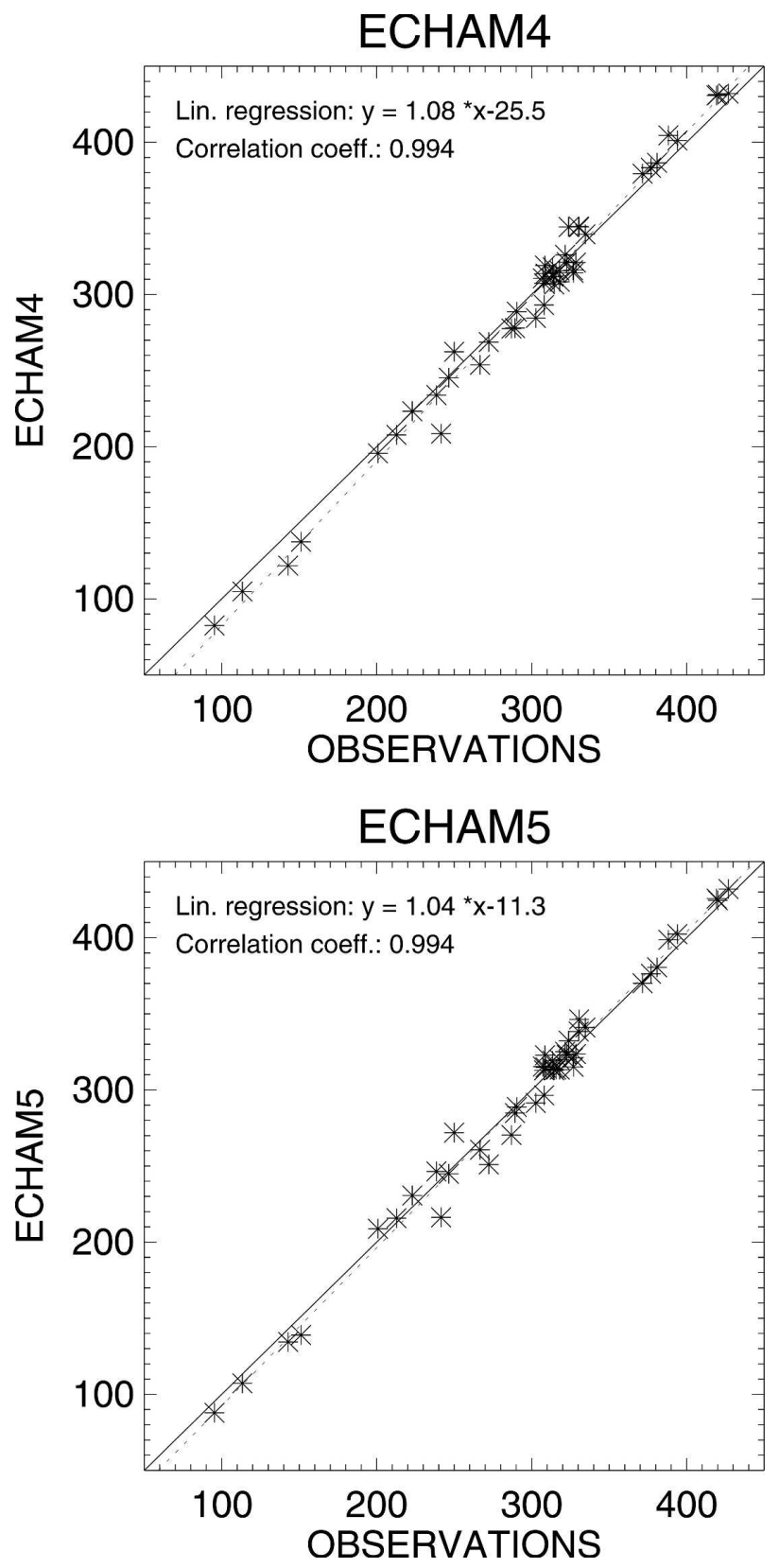

FIG. 15. Long-term annual mean downward longwave fluxes calculated with ECHAM4 and ECHAM5 vs observations at 45 observation sites from GEBA and BSRN. Units: $\mathrm{W} \mathrm{m}^{-2}$. 


\section{HIGH LATITUDE SITES}
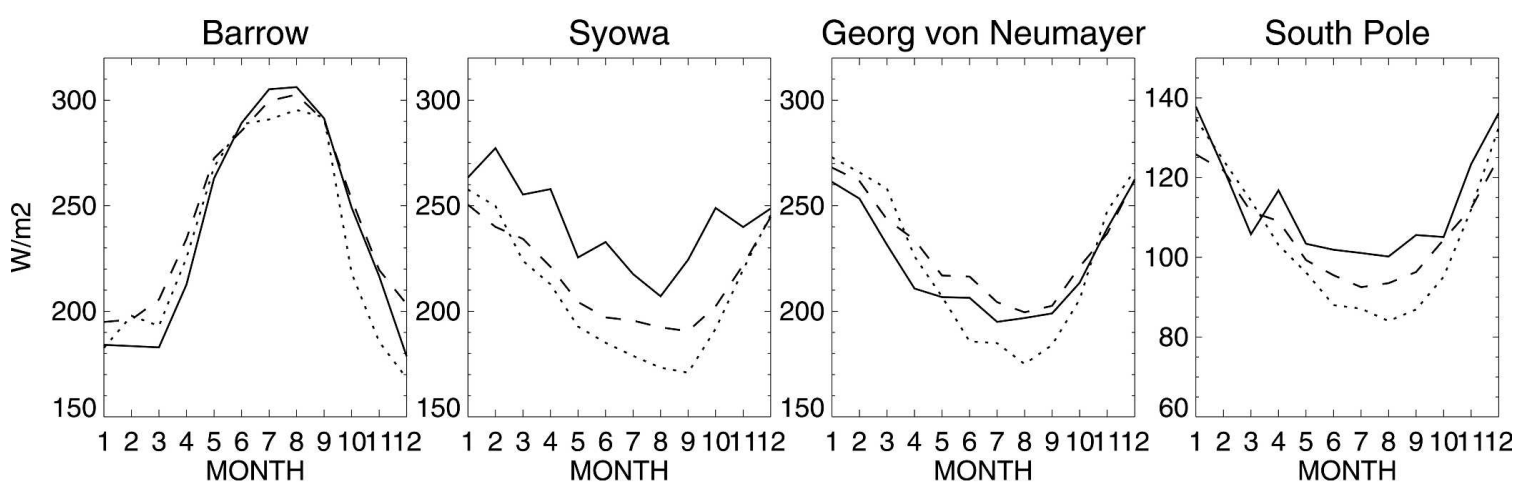

MID LATITUDE SITES
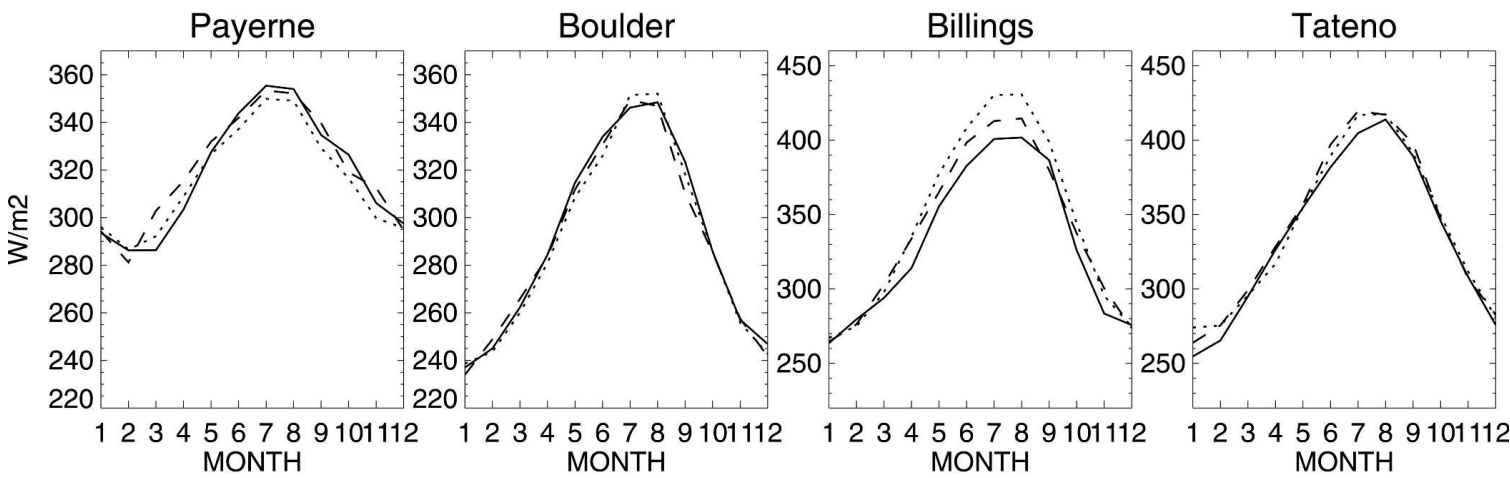

LOW LATITUDE SITES

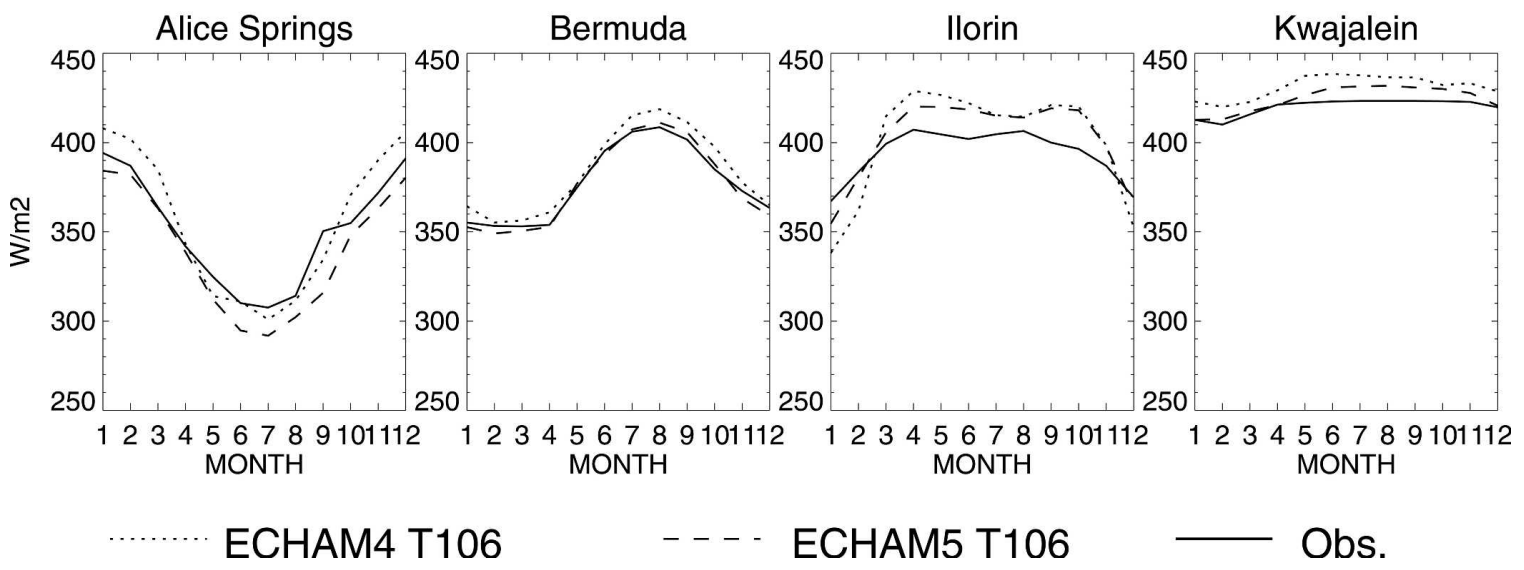

FIG. 16. Annual cycles of model-calculated and observed downward longwave radiation at some of the most reliable high-latitude sites, midlatitude sites, and low-latitude sites from BSRN. Model calculations by ECHAM4 (dotted) and ECHAM5 (dashed) are compared to observations (solid). Units: $\mathrm{W} \mathrm{m}^{-2}$.

which leads to an increase in the DLR under cold and dry conditions. As a consequence, the DLR in ECHAM5 is enhanced at high latitudes compared to ECHAM4. This is evident from the zonal mean distribution of DLR in ECHAM4 and ECHAM5 shown in Fig. 14. It can be further noted that the DLR is somewhat reduced in low latitudes compared to ECHAM4. This results in a reduction of the meridional gradient of DLR, which was found to be too large in many GCMs (Wild et al. 2001). An increase of DLR in cold regions was also found in Iacono et al. (2000) when introducing the RRTM into the NCAR Community Climate Model.

In Fig. 15, long-term annual mean fluxes calculated in 
ECHAM5 are compared with observed long-term means determined at 45 observation sites from GEBA and BSRN. A good agreement can be noted, with biases smaller than typically found in GCMs, particularly for fluxes with low values (Fig. 15). Improvements are also seen in the simulated annual cycles of DLR at various BSRN sites at high, middle, and low latitudes (Fig. 16). These results are in line with the findings in Morcrette (2002a) based on the ECMWF forecasting system. Compared to ECHAM4, the ECHAM5 reduces both the underestimation at high-latitude sites and the overestimation at low-latitude sites significantly. While the DLR in ECHAM4 was already improved compared to ECHAM3 (Wild et al. 1998, 2001), the ECHAM5 simulation is a further step toward a realistic representation of the DLR.

\section{Conclusions}

Radiative fluxes from both the top of the atmosphere and the surface have been assessed for ECHAM5. At the top of the atmosphere, the global and zonal mean radiative fluxes are generally in good agreement with those of ERBE satellite data. Deviation from ERBE in global mean cloud forcing has been introduced deliberately, through model tuning, for obtaining a balance between absorbed shortwave radiation and emitted longwave radiation in the long-term global mean. Errors in the regional distribution of the cloud forcing are larger for the shortwave component than for the longwave component and more pronounced in the Tropics than in the extratropics. In boreal summer, for example, the SWCF is too high in the ITCZ regions over both oceans and continents. This bias is consistent with enhanced rainfall in these regions (HAR) suggesting anomalously strong dynamic or convective forcing as the main source of error. In boreal winter the most apparent model deficiencies are the underestimated SWCF in the stratocumulus regimes off the west coasts of Peru, Angola, and Western Australia and the negative biases in both LWCF and SWCF in the Maritime Continent. The negative rainfall bias in this region (HAR) is indicative of a too weak dynamic/convective forcing. At lower latitudes, except in the marine stratocumulus regimes, the LWCF is generally too small while the SWCF is generally too large so that the net cloud forcing becomes too negative. This is an indication of an incorrect vertical cloud distribution with overestimated low and middle water clouds and underestimated cirrus clouds.

Using observational data from the GEBA and BSRN databases, it is shown that ECHAM5 calculates im- proved surface fluxes of both shortwave and longwave radiation compared to its precursor versions and other GCMs. This is of particular relevance for the coupling of ECHAM5 to other components of the climate system, as designated for the Community Earth System Models Project (COSMOS; details available online at http://cosmos.enes.org). In the shortwave, the increase of the number of bands in the radiation code from two to four resulted in an improvement of the overall atmospheric absorption in general and cloud absorption in particular. The absorption in the clear-sky atmosphere is not sensitive to the band number increase and is shown to be in good agreement with newly available observational clear-sky climatologies. Remaining biases in the ECHAM5 shortwave atmospheric absorption can be attributed to the crude aerosol climatology used in the ECHAM5 standard version. This climatology does not take into account large regional and seasonal loadings of absorbing aerosol as, for example, observed during periods of widespread biomass burning. A sophisticated aerosol model has been developed for ECHAM5 (Stier et al. 2005) that may be able to remove these biases.

In the longwave, the introduction of a new radiation code (RRTM) was demonstrated to have a beneficial impact on the simulated downward longwave radiation. This code calculates increased downward longwave radiation under cold and dry conditions at high latitudes, thereby reducing its meridional gradient known to be excessive in many GCMs. These changes in downward longwave radiation significantly reduce the biases compared to the available surface observations from the GEBA and BSRN datasets.

Acknowledgments. We are grateful to Drs. Atsumu Ohmura, Hans Gilgen, and Andreas Roesch for their efforts to establish and maintain the GEBA and BSRN databases. The BSRN clear-sky climatologies have been developed in collaboration with Dr. Chuck Long. This study is supported by the National Centre of Competence in Climate Research (NCCR Climate), sponsored by the Swiss National Science Foundation. The Swiss Centre for Scientific Computing (CSCS) supported the high-resolution ECHAM experiments.

\section{REFERENCES}

Arino, O., and J.-M. Melinotte, 1998: The 1993 Africa Fire Map. Int. J. Remote Sens., 19, 2019-2023.

Barkstrom, B. R., E. F. Harrison, and R. B. Lee III, 1990: Earth Radiation Budget Experiment. Eos, Trans. Amer. Geophys. Union, 71, 297-305.

Chen, C.-T., and E. Roeckner, 1996: Validation of the earth ra- 
diation budget as simulated by the Max Planck Institute for Meteorology general circulation model ECHAM4 using satellite observations of the Earth Radiation Budget Experiment (ERBE). J. Geophys. Res., 101, 4269-4287.

Clough, S. A., F. X. Kneizys, and R. W. Davies, 1989: Line shape and the water vapour continuum. Atmos. Res., 23, 229-241.

Darnell, W. L., W. F. Staylor, S. K. Gupta, N. A. Ritchey, and A. C. Wilber, 1992: Seasonal variation of surface radiation budget derived from International Satellite Cloud Climatology Project C1 data. J. Geophys. Res., 97, 15 741-15 760.

DeLuisi, J., K. Dehne, R. Vogt, T. Konzelmann, and A. Ohmura, 1992: First results of the Baseline Surface Radiation Network (BSRN) broadband infrared radiometer intercomparison at FIREII. Proc. Int. Radiation Symp., Tallinn, Estonia, 559564

Ebert, E. E., and J. A. Curry, 1993: An intermediate onedimensional thermodynamic sea ice model for investigating ice-atmosphere interactions. J. Geophys. Res., 98, 10 08510109.

Fouquart, Y., and B. Bonnel, 1980: Computations of solar heating of the Earth's atmosphere: A new parameterization. Beitr. Phys. Atmos., 53, 35-62.

Gilgen, H., and A. Ohmura, 1999: The Global Energy Balance Archive. Bull. Amer. Meteor. Soc., 80, 831-850.

—, M. Wild, and A. Ohmura, 1998: Means and trends of shortwave irradiance at the surface estimated from Global Energy Balance Archive data. J. Climate, 11, 2042-2061.

Gupta, S. K., N. A. Ritchey, A. C. Wilber, and C. H. Whitlock, 1999: A climatology of surface radiation budget derived from satellite data. J. Climate, 12, 2691-2710.

Hagemann, S., K. Arpe, and E. Roeckner, 2006: Evaluation of the hydrological cycle in the ECHAM5 model. J. Climate, 19, 3810-3827.

Hense, A., M. Kerschgens, and E. Raschke, 1982: An economical method for computing radiative transfer in circulation models. Quart. J. Roy. Meteor. Soc., 108, 231-252.

Iacono, M. J., E. J. Mlawer, S. A. Clough, and J. J. Morcrette, 2000: Impact of an improved longwave radiation model, RRTM, on the energy budget and thermodynamic properties of the NCAR Community Climate Model, CCM3. J. Geophys. Res., 105, 14 873-14 890.

Kiehl, J. T., 1994: On the observed near cancellation between longwave and shortwave cloud forcing in tropical regions. $J$. Climate, 7, 559-565.

—_, and K. E. Trenberth, 1997: Earth's annual global mean energy budget. Bull. Amer. Meteor. Soc., 78, 197-208.

Li, Z., M. Cribb, F.-L. Chang, A. Trishchenko, and L. Yi, 2005: Natural variability and sampling errors in solar radiation measurements for model validation over the Atmospheric Radiation Measurement Southern Great Plains region. J. Geophys. Res., 110, D15S19, doi:10.1029/2004JD005028.

Long, C. N., and T. P. Ackerman, 2000: Identification of clear skies from broadband pyranometer measurements and calculations of downwelling shortwave cloud effects. J. Geophys. Res., 105 (D12), 15 609-15 626.

Ma, C. C., C. R. Mechoso, A. Arakawa, and J. D. Farrara, 1994: Sensitivity of a coupled atmosphere-ocean model to physical parameterizations. J. Climate, 7, 1883-1896.

Mlawer, E. J., S. J. Taubman, P. D. Brown, M. J. Iaocono, and S. A. Clough, 1997: Radiative transfer for inhomogeneous atmospheres: RRTM, validated correlated-k model for the longwave. J. Geophys. Res., 102, 16 663-16 682.
Morcrette, J. J., 2002a: The surface downward longwave radiation in the ECMWF forecast system. J. Climate, 15, 1875-1892.

- 2002b: Assessment of the ECMWF model cloudiness and surface radiation fields at the ARM SGP site. Mon. Wea. Rev., 130, 257-277.

_ L. Smith, and Y. Fouquart, 1986: Pressure and temperature dependence of the absorption in longwave radiation parameterizations. Beitr. Phys. Atmos., 59, 455-469.

Ohmura, A., and H. Gilgen, 1993: Re-evaluation of the global energy balance. Interactions between Global Climate Subsystems: The Legacy of Hann, G. McBean and M. Hantel, Eds., Geophys. Monogr., Vol. 75, Amer. Geophys. Union, 93-110.

— and Coauthors, 1998: Baseline Surface Radiation Network (BSRN/WCRP): New precision radiometry for climate research. Bull. Amer. Meteor. Soc., 79, 2115-2136.

Philipona, R., and Coauthors, 1998: The Baseline Surface Radiation Network pyrgeometer round-robin calibration experiment. J. Atmos. Oceanic Technol., 15, 687-696.

Raschke, E., A. Ohmura, W. B. Rossow, B. E. Carlson, Y.-C. Zhang, C. Stubenrauch, M. Kottek, and M. Wild, 2005: Cloud effects on the radiation budget based on ISCCP data (19911995). Int. J. Climatol., 25, 1103-1125.

Roeckner, E., and Coauthors, 1992: Simulation of the present-day climate with the ECHAM model: Impact of model physics and resolution. Max Planck Institute for Meteorology Rep. 93, 171 pp. [Available from MPI für Meteorologie, Bundesstr. 53, D-20146 Hamburg, Germany.]

_ , and Coauthors, 1996: The atmospheric general circulation model ECHAM4: Model description and simulation of present day climate. Max Planck Institute for Meteorology Rep. 218, 130 pp. [Available from MPI für Meteorologie, Bundesstr. 53, D-20146 Hamburg, Germany.]

— , and Coauthors, 2003: The atmospheric general circulation model ECHAM5. Part 1: Model description. Max Planck Institute for Meteorology Rep. 249, 140 pp. [Available from MPI für Meteorologie, Bundesstr. 53, D-20146 Hamburg, Germany.]

_ , and Coauthors, 2006: Sensitivity of simulated climate to horizontal and vertical resolution in the ECHAM5 atmosphere model. J. Climate, 19, 3771-3791.

Stier, P., and Coauthors, 2005: The aerosol-climate model ECHAM5-HAM. Atmos. Chem. Phys., 5, 1125-1156.

Tanré, D., J.-F. Geleyn, and J. M. Slingo, 1984: First results of the introduction of an advanced aerosol-radiation interaction in the ECMWF low resolution global model. Aerosols and Their Climatic Effects, H. Gerber and A. Deepak, Eds., A. Deepak, 133-177.

Wielicki, B. A., B. R. Barkstrom, E. F. Harrison, R. B. Lee III, G. L. Smith, and J. E. Cooper, 1996: Clouds and the Earth's Radiant Energy System (CERES): An earth observing system experiment. Bull. Amer. Meteor. Soc., 77, 853-868.

Wild, M., 1999: Discrepancy between model-calculated and observed atmospheric shortwave absorption in areas with high aerosol loadings. J. Geophys. Res., 104 (D22), 27 361-27 371.

- 2000: Absorption of solar energy in cloudless and cloudy atmospheres over Germany and in GCMs. Geophys. Res. Lett., 27, 959-962.

_ 2001: Surface and atmospheric radiation budgets as determined in reanalyses. IRS2000: Current Problems in Atmospheric Radiation, W. L. Smith and Yu. M. Timofeyev, Eds., A. Deepak, 602-605. 
- 2 2005: Solar radiation budgets in atmospheric model intercomparisons from a surface perspective. Geophys. Res. Lett., 32, L07704, doi:10.1029/2005GL022421.

_ - A. Ohmura, H. Gilgen, and E. Roeckner, 1995a: Validation of GCM simulated radiative fluxes using surface observations. J. Climate, 8, 1309-1324.

$-, \ldots, \ldots$, and $\_, 1995$ b: Regional climate simulation with a high resolution GCM: Surface radiative fluxes. Climate Dyn., 11, 469-486.

,,$---\longrightarrow$, M. Giorgetta, and J. J. Morcrette, 1998:
The disposition of radiative energy in the global climate system: GCM-calculated versus observational estimates. Climate Dyn., 14, 853-869.

- — - — - J. J. Morcrette, and A. Slingo, 2001: Downward longwave radiation in general circulation models. J. Climate, 14, 3227-3239.

, C. N. Long, and A. Ohmura, 2006: Evaluation of clear-sky solar fluxes in GCMs participating in AMIP and IPCC-AR4 from a surface perspective. J. Geophys. Res., 111, D01104, doi:10.1029/2005JD006118. 